University of Wollongong

Research Online

Faculty of Engineering and Information

Faculty of Engineering and Information

Sciences - Papers: Part B

Sciences

2018

Laboratory investigation into biodegradation of jute drains with implications for field behavior

Thanh Trung Nguyen

University of Wollongong, ttnguyen@uow.edu.au

Buddhima Indraratna

University of Wollongong, indra@uow.edu.au

John Philip Carter

University of Newcastle

Follow this and additional works at: https://ro.uow.edu.au/eispapers1

Part of the Engineering Commons, and the Science and Technology Studies Commons

Research Online is the open access institutional repository for the University of Wollongong. For further information contact the UOW Library: research-pubs@uow.edu.au 


\title{
Laboratory investigation into biodegradation of jute drains with implications for field behavior
}

\begin{abstract}
Naturally occurring materials such as jute and coir have some favorable engineering characteristics and also degrade over time, so they have increasingly been used in engineering applications in recent years. The efficient way that naturally prefabricated vertical drains made from those materials help accelerate soil consolidation has been shown in previous studies, but they also tend to decompose rapidly in adverse environments, where cellulose-degrading bacteria cause a serious deterioration of their favorable drainage properties. This study presents a laboratory investigation into the biodegradation of prefabricated vertical jute drains in saturated soft soils, where the tensile strength of jute and coir fibers and the discharge capacity of drains decrease in response to different environments. Micro-observation also shows a transformation of the jute fibers and destruction of the drain structure due to biodegradation. DNA extraction and sequencing techniques to determine the microbial properties of these decayed fibers indicate that bacteria such as species of the genera Clostridium and Bacillus can cause rapid decomposition of cellulose-based material (i.e., jute), whereas other organic matterconsuming microbes such as sulfate-reducing bacteria do not directly contribute to the biodegradation of jute. In response, an analytical approach that incorporates various forms of drain discharge capacity over time is proposed to predict soil consolidation. The results indicate there is considerable deviation in dissipating the excess pore pressure when the drain degrades in different ways.

\section{Disciplines}

Engineering | Science and Technology Studies

\section{Publication Details}

Nguyen, T. Trung., Indraratna, B. \& Carter, J. (2018). Laboratory investigation into biodegradation of jute drains with implications for field behavior. Journal of Geotechnical and Geoenvironmental Engineering, 144 (6), 04018026-1-04018026-15.
\end{abstract}




\title{
LABORATORY INVESTIGATION INTO BIODEGRADATION OF JUTE DRAINS WITH IMPLICATIONS FOR FIELD BEHAVIOUR
}

\author{
Thanh Trung Nguyen \\ PhD student, \\ Centre for Geomechanics and Railway Engineering, University of Wollongong, \\ Wollongong City, NSW 2522, Australia
}

\section{Buddhima Indraratna ${ }^{1}$}

BSc (Hons., Lond.), MSc (Lond.), DIC, PhD (Alberta), FTSE, FIEAust., FASCE, FGS

Distinguished Professor of Civil Engineering,

Faculty of Engineering and Information Sciences,

Director, Centre for Geomechanics and Railway Engineering, University of Wollongong, Wollongong City, NSW 2522, Australia

\begin{abstract}
John Carter
Emeritus Professor, Faculty of Engineering and Built Environment, University of Newcastle, Callaghan, NSW, 2308, Australia
\end{abstract}

Words: 8506

Figures: 18

Submitted to: Journal of Geotechnical and Geoenvironmental Engineering ASCE

${ }^{1}$ Corresponding author: Buddhima Indraratna (e-mail: indra@uow.edu.au) 


\section{LABORATORY INVESTIGATION INTO BIODEGRADATION OF} JUTE DRAINS WITH IMPLICATIONS FOR FIELD BEHAVIOUR

\section{Abstract}

4 Naturally occurring materials such as jute and coir have some favourable engineering 5 characteristics and also degrade over time, so they have increasingly been used in engineering 6 applications in recent years. The efficient way that naturally prefabricated vertical drains 7 (NPVDs) made from those materials help accelerate soil consolidation has been shown in 8 previous studies, but they also tend to decompose rapidly in adverse environments where 9 cellulose degrading bacteria cause a serious deterioration of their favourable drainage properties. This study presents a laboratory investigation into the biodegradation of 11 prefabricated vertical jute drains (PVJDs or jute drains) in saturated soft soils, where the 12 tensile strength of jute and coir fibres and the discharge capacity of drains decrease in 13 response to different environments. Micro-observation also shows a transformation of the jute 14 fibres and destruction of the drain structure due to biodegradation. DNA extraction and sequencing techniques to determine the microbial properties of these decayed fibres indicate

16 that bacteria such as species of the genera Clostridium and Bacillus can cause a rapid 17 decomposing of the cellulose-based material (i.e., jute), while other organic matter consuming microbes such as sulphate reducing bacteria do not directly contribute to the

19 biodegradation of jute. In response, an analytical approach that incorporates various forms of drain discharge capacity over time is proposed to predict soil consolidation. The results

21 indicate there is a considerable deviation in dissipating the excess pore pressure when the 22 drain degrades in different ways.

23 Keywords: natural prefabricated vertical drains; consolidation; natural fibres; biodegradation; discharge capacity. 


\section{Introduction}

Soil improvement using natural prefabricated vertical drains (NPVDs) (also known as

27 natural fibre drains) has been carried out in several regions, especially in South and Southeast

28 Asia, ever since the first NPVD was introduced by Lee et al. (1987). Many field observations

29 (Lee et al. 1994; Lee et al. 2003; Kim and Cho 2008) have shown that NPVDs with

30 favourable engineering characteristics such as excellent discharge capacity and resistance to

31 deformation, i.e., bending and kinking are a viable alternative to synthetic prefabricated

32 vertical drains (SPVDs) made from polymeric materials which are seen as possibly having an

33 adverse effect on the natural environment (Gregory and Andrady 2003). However, many of

34 these applications were in inert soils, which may not harm the engineering properties of the

35 drains, so their biodegradation characteristics have not received any serious attention. Under

36 adverse environments such as bioactive soils, in which cellulose degrading microorganisms

37 exist, the decay process of cellulose-based materials such as jute is very serious; for example,

38 Miura et al. (1995) show a severe degradation of a jute fibre drain buried in Ariake clay

39 where the drain lost almost $78 \%$ of its tensile strength after only 126 days. Because saturated

40 soft soils, especially alluvial soils which normally have a large organic content and complex

41 biological profiles, are the areas where NPVDs are most likely to be considered for ground

42 improvement, there is an urgent need to evaluate the biodegradation of these drains in those

43 conditions.

44 While raw natural fibres such as jute and coir can be used to make NPVDs which are

45 normally band-shaped with a number of coir cores wrapped by layers of jute geotextiles (Fig.

46 1a), the straw which is a sub-product of rice fields and very popular in Asian countries is used

47 to create circular drains, as Kim and Cho (2008) describe. This study shows that straw fibre

48 drains have a lower discharge capacity than jute fibre drains but they can still discharge

49 excess pore pressure at an acceptable rate. Jute and coir are the most commonly used 
50 materials to manufacture drains because they have distinct engineering characteristics such as

51 durability and high hydraulic conductivity, and are also abundant in many developing

52 countries where the demand for ground improvement is often high. Jute has more than $80 \%$

53 cellulose and only around 12\% lignin (Som et al. 2009), making the fibre less durable than

54 coir which has approximately 40\% lignin and 43\% cellulose (Gupta 2011). Those chemical

55 features also indicate that the biodegradation of jute depends primarily on the decomposition

56 of cellulose, while lignin plays a key role in the decomposition of coir.

57 There are a number of key factors affecting the decomposition of organic matter such

58 as jute and straw, these include: $(i)$ the chemical properties of the material; which means the

59 more lignin, the more durable the fibre, and (ii) environmental conditions such as

60 temperature, humidity, chemical components and activities of microorganisms. A pilot

61 project by Kim and Cho (2008) reports a much faster decomposition of NPVDs in warmer

62 seasons where microorganisms are more active due to the higher temperature. Laboratory

63 investigations (Som et al. 2009; Saha et al. 2012) indicate a large impact of the acidity in the

64 environment on the biodegradation of jute fibre. However, these studies consider the

65 influence of the chemical (e.g., acidity), physical (e.g., humidity and temperature), and

66 biological (e.g., bacteria) factors on the fibre degradation independently, whereas natural

67 fibres used to improve soft soil are usually subjected to those factors simultaneously, so the

68 degradation of drains in the field is more complicated. While the biodegradation of naturally

69 occurring materials is an unavoidable issue when using them in practice, there is a lack of

70 studies addressing the mechanism of biodegradation that natural fibres such as jute and coir

71 undergo in saturated soft soil. It is therefore important to clarify how the biodegradation can

72 occur in those media and under which conditions caution in the field is needed.

73 Indraratna et al. (2016) have evaluated the effect that the biodegradation of NPVDs

74 can have on the consolidation of soil by considering an exponential reduction in the discharge 
75 capacity of drains. This study indicates that the dissipation of excess pore pressure can be

76 severely retarded due to biodegradation in the drain, and also indicates there is a need to

77 exercise caution when installing NPVDs in adverse soils. The current study seeks to further

78 clarify the mechanism of drain biodegradation through a laboratory investigation, where

79 prefabricated vertical jute drains (PVJDs) are buried in saturated soft clays. The reduction in

80 the tensile strength of this fibre is recorded over time and there is an intensive biological

81 analysis using the genomic sequencing technique to identify microbes which consume the

82 natural fibres. The results are then used to improve the analytical method to predict soil

83 consolidation proposed by Indraratna et al. (2016).

\section{Laboratory investigation into the biodegradation of NPVDs}

This section presents the findings of a laboratory investigation into the biodegradation

of natural fibre drains buried in different types of saturated soft clay obtained from the field.

87 Of the existing NPVDs, prefabricated vertical jute drains (PVJDs) are the most commonly

88 used, as many previous studies indicate (Lee et al. 1994; Lee et al. 2003; Kim and Cho 2008;

89 Asha and Mandal 2015). A typical PVJD, which is usually 8 to $12 \mathrm{~mm}$ thick and 100 to 120

90 mm wide, includes 4 to 5 coconut cores wrapped by 1 to 2 layers of jute sheath (Fig. $1 \mathrm{a})$ to

91 make the filter layer. Jute and coir bundles making the drain are created from individual

92 fibres which are extracted from jute plants and coconut husks (Rahman 2010; Gupta 2011).

93 Common jute geotextiles which are used as the filter have an apparent opening size (AOS)

94 that varies from 100 to $400 \mu \mathrm{m}$ which is much larger than the size of clay particles. In this

95 structural format, jute fibre plays a major role in the discharge capacity of the drains.

\section{Experimental scheme}

Clay soil was collected from 1.5 to $1.8 \mathrm{~m}$ deep layers at the National Soft Soil Field

98 Testing Facility (NFTF) at Ballina, Australia. The water content of these natural soils varied 
99 from 57 to $65 \%$ and there was a neutral acidic level (pH from 6.2 to 7.2). Their organic 100 content varied from 3.5 to $4.2 \%$ which was slightly larger than those measured in Ballina

101 clay by Pineda et al. (2016). The salinity of pore water extracted from natural soil was 102 approximately $16 \mathrm{~g} / \mathrm{l}$, as revealed by an electrical conductivity measurement. Pineda et al. 103 (2016) show there is a small concentration of ion (i.e., $\mathrm{Fe}^{2+}$ and $\mathrm{Mg}^{2+}$ with less than $1.0 \mathrm{~g} / \mathrm{l}$ ) 104 and a larger amount of sodium (1-2.5 g/l) and chloride (2-4 g/l) in the 1.5-2 $\mathrm{m}$ deep soil at 105 Ballina.

106 This soil was then reconstituted using neutral water and commercial vinegar (acetic 107 acid) with a $\mathrm{pH}$ of 2.9 to create different environmental conditions. The acidity was managed 108 with a portable $\mathrm{pH}$ meter (Spectrum Technologies Int 2011). Three cases were generated with 109 the following details:

110 (i) Soil/Container 1: Natural soil mixed with neutral water with a $\mathrm{pH}$ of 6.8 to create a 111 sample having a pH of approximately 6.4 and a water content of $90.6 \%$.

112 (ii) Soil/Container 2: Natural soil mixed with vinegar and neutral water to form a 113 reconstituted medium having an average $\mathrm{pH}$ of 4.8 and water content of $91.3 \%$.

114 (iii) Soil/Container 3: Natural soil mixed with vinegar to form a medium with an average $\mathrm{pH}$ of 3.5 and a water content of $93.8 \%$.

116 The oxidation reduction (or redox) potential test that is widely used to measure the 117 propensity of a solution to contribute or accept electrons was carried out on the above media 118 over time. The index obtained from these tests indicates the concentration of oxidants (e.g., 119 oxygen, manganese, iron, sulphate) and reductants which play an important role in many 120 reactions of biological systems (Delaune and Reddy 2005). A more negative redox potential 121 represents a lower concentration of oxidants and a more anaerobic condition of soil where its 122 microbial characteristics will change over the biochemical reaction which regulates the 123 metabolism of microorganisms in the medium. This parameter was measured with a meter 
124 using a platinum tip probe (TPS 2012).

A number of PVJD samples were buried in the above soil samples (Fig. 1b), and their

126 containers were kept in a conditioned dark room at $22^{\circ} \mathrm{C}$ and $88 \%$ relative humidity. This

127 ensured that physical parameters such as temperature, light, and humidity remained constant

128 over time and the same in every sample. After specific periods of time, i.e., 15, 30, 60, 120,

$129180,240,300,520$ and 630 days, the samples were removed and then subjected to tension 130 and discharge capacity tests to determine whether or not they had degraded. The acidity $(\mathrm{pH})$

131 and ORP of the media were noted respectively.

\section{Tension tests on fibre drains}

Tensile strength of fibre drains was measured over time to evaluate how different

134 environments had influenced on their engineering properties. These tension tests were carried 135 out on the complete drain and individual fibres (coir and jute) extracted from the drain (Fig.

136 2). The diameter of single fibres was determined by microscope and their tensile strength was

137 calculated by referring to the applied tension force and corresponding cross-sectional area; in

138 this process, variation in the tensile strength of single fibres was obtained. Since the coir

139 fibres were sufficiently large, the tensile strength can be measured by testing individual fibres

140 whereas with the jute fibres, this parameter was obtained via a tension test on bundles of 141 fibres. The average tensile strength of jute fibre was then estimated on the basis of the tension 142 force of the whole bundle and the total cross-sectional area of individual fibres in the bundle.

143 In this investigation, the equivalent diameter of jute fibre varied from 12 to $78 \mu \mathrm{m}$

144 while coir fibre was much larger and its diameter varied from 109 to $512 \mu \mathrm{m}$. The aspect 145 ratio (the ratio of length to diameter) of jute and coir fibres varied approximately from 350 to 1468000 and 200 to 1600 , respectively. Note that physical properties of jute fibres which are 147 composed of ultimate cells having the size from 0.7 to $6 \mathrm{~mm}$ in length and 10 to $25 \mu \mathrm{m}$ in 148 diameter (Gupta 2011) are strongly influenced by manufacture processes, i.e., retting and 
149 extraction. For each stage of tensile strength testing, tests were carried out on 20 samples to

150 ensure the reported result was accurate and representative. The initial tensile strength of

151 fibres was assumed to be identical because all the samples of fibre drains studied in this

152 investigation were extracted from the same manufactured package. The average tensile

153 strength of fresh jute and coir in this study was $480 \pm 38 \mathrm{MPa}$ and $172 \pm 27 \mathrm{MPa}$,

154 respectively, which corroborate values reported in previous studies (Defoirdt et al. 2010;

155 Gupta 2011).

156 Discharge capacity test on fibre drains

To determine how the discharge capacity of fibre drains had changed over time and

158 different soil conditions, a discharge capacity test which was established with reference to the 159 testing model used in previous studies (Jang et al. 2001) was carried out on the drains 160 extracted (Fig. 3a). In this investigation, the drain was wrapped by a membrane and placed 161 vertically in a cell in which the confining pressure applied on the drain was managed via cell 162 pressure (Fig. $3 \mathrm{~b}$ and c). The inlet water was generated by a constant head tank while the 163 discharge volume at the outlet was recorded over time. The hydraulic gradient was controlled 164 by the difference in water heads between the inlet and outlet. Manometers with an accuracy 165 of $1 \mathrm{~mm}$ were used to measure water heads at the inlet and outlet of the drain. The discharge 166 capacity of drain was calculated on the basis of the hydraulic gradient and discharge volume 167 at the outlet of the drain with respect to ASTM D4716 (2008).

168 Note that in this investigation, a layer of soil remained on drains after extracting 169 from containers was kept during confining. By this approach, the influence of soil, e.g., 170 clogging on hydraulic conductivity of fibre drains was included. The hydraulic gradient was 171 generated from 0.1 to 0.5 which was close to field condition as suggested by Chu et al. 172 (2004). The confining pressure including 10, 50 and $100 \mathrm{kPa}$ was applied in this study. 


\section{Microbial analysis of degraded natural fibres}

174 To obtain an insight into the biodegradation of a fibre drain, an uncultured approach

175 known as DNA sequencing was applied to microorganisms in the samples (Fig. 4). Bio-

176 molecular techniques have been used extensively over recent decades to identify

177 microorganism in soil, as seen in studies by Kirk et al. (2004), Liu et al. (2006) and Maron et

178 al. (2011). In this study, the Illumina sequencing technique was used. This Next Generation

179 Sequencing (NGS) technique has been developed intensively and applied widely in recent

180 years to profile the microbial community due to its low cost and time efficiency (Barba et al.

$1812014)$.

182 Fibres with surrounding soil particles were extracted from the containers (Fig. 3a) and

183 then maintained in freezing conditions because the microbial characteristics can be preserved

184 well at freezing temperatures, as Rubin et al. (2013) show. The extraction and purification of

185 DNA were carried out with a Powersoil DNA Isolation kit in accordance with its

186 manufacture's protocol (MO BIO Laboratories Inc); this technique has proved its efficiency

187 for many soils (Mahmoudi et al. 2011). The raw DNA extracted was then subjected to the

188 Polymerase Chain Reaction (PCR) technique to specify and amplify the DNA (Singh et al.

189 2014), and the DNA read and analysis were further processed. Microbial profiles were then

190 obtained by assigning the sequence data to the Greengenese database (DeSantis et al. 2006).

191 By this approach the identification with quantitative data and characterisation of the

192 microorganisms responsible for the biodegradation of the natural fibres (i.e., jute and coir)

193 were clarified. Note that this microbial data presents population of different microbes over

194 different samples however it does not quantitatively link to mechanical behaviours such as

195 the discharge capacity of drains and consolidation of soil in this study. 
$198 \quad$ Variations in tensile strength of jute and coir fibres subjected to different soft soil 199 conditions over time is shown in Fig. 5a; these results came from samples extracted from the 200 different containers, but at the same depth (i.e., $40 \mathrm{~cm}$ ). Jute buried in soil 1 has a faster 201 reduction in tensile strength than samples exposed to soils 2 and 3. After approximately 70 202 days, variations in the tensile strength of jute were almost the same in every case, and are 203 insignificant, but the reduction curves clearly deviated after this period. Soil 1 has the fastest 204 reduction, with the average tensile strength of jute decreasing from $480 \mathrm{MPa}$ to $315 \mathrm{MPa}$ and $20573 \mathrm{MPa}$ after 150 days and 300 days, respectively; in particular the fibre loses almost $90 \%$ of 206 its initial tensile strength after 500 days. This reduction in the tensile strength of jute is much

207 less severe in soils 2 and 3, and while the jute in soil 2 maintains approximately $48 \%$ of its 208 initial strength after 520 days, almost $80 \%$ of the tensile strength of the fibre buried in soil 3 209 remains after the same time period.

210 The results of a tension test on fibres located $5 \mathrm{~cm}$ deep in soil 1 are shown as the 211 dashed curve in Fig. 5a; note that these fibres degrade much more than those deeper down in 212 the same container. The tensile strength of fibre in the surface soil decreases to almost 25

$213 \mathrm{MPa}$ after about 300 days and $100 \%$ of its original value disappears after around 500 days.

214 This indicates there is a considerable deviation in the rate and amount of reduction in tensile 215 strength at different depths in the same soil. These results also show that the decrease in 216 tensile strength of jute only becomes apparent after around 70 days in saturated soil.

217 Unlike the severe deterioration of jute described above, coir does not show significant 218 reduction in its tensile strength (Fig. 5b). In fact it retains more than $80 \%$ its original tensile 219 strength after nearly 600 days and there is no significant deviation in the reduction curves of 220 fibres exposed to different saturated soils, which indicates that coir resists degradation far 
221 better than jute.

222 Fig. 5 b shows the reduction in tensile strength of the whole drain which includes both

223 jute and coir fibres in complete form (Fig. 1a); in the first nearly 70 days the decrease in

224 tensile strength is insignificant but then it becomes quite significant, particularly in soil 1

225 where the environment had a more neutral acidity. The tensile strength of the drain exposed

226 to soils 2 and 3 from 70 to 630 days decreases gradually at different rates, i.e., $2.3 \mathrm{~N} /$ day and

$2270.86 \mathrm{~N} /$ day, respectively, whereas the tensile strength of the drain in soil 1 reduces steeply to

228 approximately $1 \mathrm{kN}$ after 300 days and then gradually slows down. This occurs because the

229 tensile strength of jute fibres had decreased so much when losing nearly $85 \%$ their initial

230 tensile strength (Fig. 5a), thus making the overall strength rely mainly on the strength of the

231 coconut cores which could still maintain significantly their strength, even after 300 days. By

232 way of comparison, Miura et al. (1995) have shown how jute drains installed in Ariake clay

233 lost $78 \%$ of their initial tensile strength after only 120 days.

\section{Discharge capacity of fibre drains}

235 The recorded discharge capacity of drains over time and different confining pressures

236 is presented in Fig. 6a. It is commonly agreed that the higher the confining pressure, the

237 lower the discharge capacity. For example, in fresh condition ( 0 day) in which drains were

238 not contaminated by soil, the discharge capacity of drains decreases from 0.45 to 0.27 and

$2390.21 \mathrm{~m}^{3} /$ day as the confining pressure changes from 10 to 50 and $100 \mathrm{kPa}$, respectively. Note

240 that a slight reduction in discharge capacity occurs as time increases from 0 to 15 days

241 because soil was not included in those tests at fresh ( 0 day) condition. These results

242 corroborate with previous studies (Jang et al. 2001; Kim and Cho 2008; Asha and Mandal

243 2012) which reported the discharge capacity of natural fibre drains (e.g., jute, coconut and

244 straw fibre drains) varies from 0.39 to $3.0 \mathrm{~m}^{3} /$ day over different drains and discharge capacity

245 tests. These values are relatively smaller than those of conventional synthetic PVDs which 
246 normally have the discharge capacity from 1.2 to $9.5 \mathrm{~m}^{3} /$ day under the same confinement as

247 reported in previous studies (Jang et al. 2001; Asha and Mandal 2012).

248 The reduction in discharge capacity of drains buried in soil 2 and 3 is not significant

249 as Fig. 6a shows particularly at low confining pressure, i.e., $10 \mathrm{kPa}$. Although the reduction

250 in discharge capacity of drains in soil 1 is more apparent at $10 \mathrm{kPa}$ confining pressure, it is

251 still not considerable with approximately $80 \%$ (i.e., $0.31 \mathrm{~m}^{3} /$ day) its initial capacity remained

252 after 520 days. As the confining pressure increases to 50 and $100 \mathrm{kPa}$, the discharge capacity

253 of drains buried in different soils begins to deviate apparently. While the discharge capacity

254 of drains in soil 3 still decreases insignificantly at 50 and $100 \mathrm{kPa}$, it reduces more apparently

255 in soil 2 particularly after 300 days. Soil 1 which resulted in severe reduction in tensile

256 strength of jute fibres shows a much more significant reduction in discharge capacity of

257 drains. At $50 \mathrm{kPa}$, the discharge capacity of drains in soil 1 begins to drop clearly from 0.22

$258 \mathrm{~m}^{3} /$ day at 180 days to $0.021 \mathrm{~m}^{3} /$ day at 520 days. As the confining pressure increases to 100

$259 \mathrm{kPa}$, the discharge capacity of drains in soil 1 even falls to a smaller level at 520 days, i.e.,

$260 \quad 0.009 \mathrm{~m}^{3} /$ day.

261 The variation curve in discharge capacity of drains (Fig. 6a) includes a certain period

262 (intact period) in which the reduction in discharge capacity is insignificant over time

263 followed by a decreasing period of discharge capacity. This study reports an intact period

264 from 100 to 150 days in soil 1 but note that this can vary with different environmental (e.g.,

265 soil and temperature) and loading (confinement) conditions. The decreasing period is

266 complex with a combination of concave and convex curves however it seems to reach a

267 certain stable level after a severe reduction.

268 The above results indicate that the influence of different soil conditions on the

269 discharge capacity of drains becomes more apparent as a larger confining pressure, i.e., 50

270 and $100 \mathrm{kPa}$ is applied. This was because fibres having more degradation were less resistant 
271 to confinement, resulting in a more severe destruction in porous system of the drains. The

272 larger the confining pressure, the more fibres were compressed and rearranged, leading to the

273 smaller porosity. Ash and Mandal (2012) investigate how different porous structures of

274 NPVDs affect their discharge capacity and concluded that the stiffer the drain structure, the

275 more the resistance to confinement and the larger the discharge capacity. As fibres decayed,

276 their mechanical properties, i.e., the tensile strength reduced, making the fibre drains harder

277 to maintain their porosity under confinement. Note that the discharge capacity test could not

278 be completed on drains in soil 1 after 520 days because they were too weak and almost

279 broken after extracting from soil (Fig. 6b).

280 Further observation on jute fibres under a microscope after 520 days (Fig. 7) indicated

281 there are apparent differences between these decayed fibres exposed to different

282 environments such that the more they decay, the denser they become; in fact fibres that decay

283 due to the microorganisms metabolising tend to generate a dark compound (biomass) around

284 the fibres (Fig. 7a), which can reduce the porosity and discharge capacity of the drain. After

285 being washed, the fibres that experienced the worst damage to their structure were in soil 1,

286 while the fibres exposed to soil 3 still retain the twisting structure which plays an important

287 role in the hydraulic conductivity of fibre drains (Nguyen and Indraratna 2017a, b). This

288 indicates a considerable destruction that biodegradation can have on the microstructure of

289 natural fibre drains, which can lead to the reduction in discharge capacity of drains as shown

290 above.

291 Fig. 8 shows how different the surfaces of the soils appear after 520 days. Soil 3 does

292 not show very much biodegradation of fibres over the period under investigation, and its

293 surface still looks fresh without any significant contaminants, whereas the surfaces of soils 1

294 and 2 are covered with a layer of yellow and brown compounds, as a result of different

295 outcomes from bioactivities in those media. 
Because microbial characteristics are closely related to biochemical reactions in the

298 medium as discussed above, variations of acidity $(\mathrm{pH})$ and Oxidation Reduction Potential

299 (ORP) over time are addressed and shown in Fig. 9. It is interesting that $\mathrm{pH}$ in all soils

300 gradually increases, particularly in the period from 60 to 300 days. The neutralising medium

301 stemming from bacterial metabolism and incorporating the redox reaction has also been

302 clarified in previous studies (Inglett et al. 2005; Muyzer and Stams 2008). The ORP

303 measured at the bottom of the container decreases quickly from around $+30 \mathrm{mV}$ in the first

30430 days to a stable value of approximately $-120 \mathrm{mV}$ in the next 120 days. There is a much

305 higher ORP at the surface layer with a stable value of around $+60 \mathrm{mV}$, which indicates there

306 is a higher concentration of oxidants in this position.

307 The profiles of microorganisms in 3 media at phylum level (a genomic analysis after

308630 days at $40 \mathrm{~cm}$ depth) are shown in Fig. 10, which indicates almost the same phylum-

309 levelled bacteria but with different contributions to the media. Note that these bacteria (e.g.,

310 the phyla Firmincute and Proteobacteria) are generally the most dominant microbes found in

311 soil (Fierer et al. 2007; Berg et al. 2012). The phylum Firmincute which contains almost

312 Gram-positive bacteria (Goodfellow et al. 2009) is the largest component in soil 1 with

313 around $38 \%$ of the total microbial population, however the contribution these bacteria make

314 to the medium decreases in soil 2 and 3 with $25 \%$ and $13 \%$, respectively. In contrast, the

315 Proteobacteria predominate in soil 3 with $48.2 \%$ but are less significant in soils 2 and 1 with

$31636.4 \%$ and $26.4 \%$, respectively. The phylum Fibrobacteria accounts for a significant

317 contribution (i.e., $17.6 \%$ ) in soil 3 , but it decreases to $10.8 \%$ and $5 \%$ in soil 2 and 1 ,

318 respectively. It is also interesting to see an overwhelming role of the Firmincutes at the

319 surface layer (i.e., $98 \%$ at $5 \mathrm{~cm}$ depth) of soil 1 where the degradation was the most severe.

320 The difference these major bacteria make in the media can explain the deviation in the 
321 biodegradation process of natural fibre drains buried in such soils.

323 media with less than $10 \%$ for each. Bacteria with a contribution of less than $5 \%$ are grouped

324 into the "Others" division, as shown in the figure. Note that bacteria account for almost $99 \%$

325 of the microbial community, as identified via the genomic analysis carried out in this study.

326 The variation of major bacteria at phylum level at different values of $\mathrm{pH}$ is shown in

327 Fig. 11, where acidity in the medium makes a large contribution to the microbial properties.

328 The Firmincutes increases rapidly from around $12 \%$ at a $\mathrm{pH}$ of 4.1 to nearly $40 \%$ at a $\mathrm{pH}$ of

3297.2 whereas the Proteobacteria and Fibrobacteres decrease by approximately $20 \%$ when the

330 medium becomes more neutral. There is also a slightly larger contribution made by

331 Chloroflexi and Bacteroidetes when the $\mathrm{pH}$ increases to the neutral point. The driving role of

332 acidity in the structure of the microbial community is also discussed in previous studies by

333 Lauber et al. (2009) and Rousk et al. (2010).

334 To further clarify how the biodegradation varied when fibre drains were installed into

335 different saturated soils, an analysis at a deeper phylogenetic classification is essential

336 because bacteria at phylum level are variable in their characteristics. Note that in the

337 following discussion, because of the complexity in the microbial community, only major

338 bacteria at family and genus levels obtained from the genomic analysis are addressed with

339 respect to their bio-mechanism in decomposing organic matters. The detail of bacterial

340 community found on jute fibres buried in different saturated soils is given in Appendix A.

341 The family Ruminococaceae is the predominant member of the phylum Firmincutes

342 found in soil 1 at $40 \mathrm{~cm}$ depth (Fig. A1); these bacteria form the largest part (i.e., 29\%) of the

343 whole medium 1 but they are much less significant in soils 2 and 3 with approximately $12.6 \%$

344 and 5.2\%, respectively. These anaerobic bacteria are able to ferment carbon sources such as

345 glucose and acetate for their energy. Some species such as Acetivibrio cellulolyticus, 
346 Acetivibrio cellulosolvens and Ruminococcus flavefaciens can rapidly decompose cellulose 347 in a neutral environment (Patel et al. 1980; Goodfellow et al. 2009). The predominance of 348 these bacteria in decayed fibre buried in soil 1 indicates how quickly they cause jute fibres to 349 degenerate, as shown in the previous section, but when the medium becomes more acidic 350 (i.e., soil 2 and 3), their population decreases and the decay process of jute fibre is not as 351 serious.

There is an obvious difference of bacterial members making the phylum Firmincutes 353 at the $5 \mathrm{~cm}$ depth of soil 1 (Fig. A2); this community includes only the class Bacilli (57.31\%) 354 and Clostridia (40.69\%) in which the genus Bacillus and the Clostridium account for more 355 than $40 \%$ of their population, respectively. Previous studies (Leschine 1995; Trivedi et al. 356 2011) show that these bacteria can secrete the cellulace enzyme to ferment and break down 357 the cellulose structure into basic unit glucose. Rahman (2010) in his review over the 358 biodegradaion of jute during retting also pointed out the major contribution of these bacteria 359 to the degradation. Many species of the Clostridium such as Papyrosolvens, Lentocellum and 360 Cellobioparum are commonly found in estuarine sediments and soil (Leschine 1995).

361 The class Beta-, Gama- and Delta-Proteobacteria, which are members of the phylum 362 Proteobacteria, are also major contributors to the media. Particularly the Deltaproteobacteria 363 shares about $23.8 \%, 27.2 \%$ and $19.4 \%$ of the whole medium 1,2 and 3 , respectively while 364 the Beta- and Gama-proteobacteria also occupy $12.4 \%$ and $9.8 \%$, respectively of the 365 microbial community in soil 3. Most families of these anaerobic bacteria such as 366 Desulfobulbaceae making $66.8 \%$ of the Deltaproteobacteria in soil 1, Desulfarculaceace and 367 Desulfovibrionaceae accounting for $32.2 \%$ and $46.7 \%$, respectively of the 368 Deltaproteobacteria in soil 2 can utilise sulphate, sulphur, or other oxidised sulphur 369 compounds as electron acceptors for their metabolism (Barton and Hamilton 2007; Muyzer 370 and Stams 2008). The prevalence of those microbes in the soils is understandable because 
371 alluvial and marine soils such as Ballina clay are normally rich in the oxidised sulphur 372 compounds which are vital for their metabolism (Barton and Hamilton 2007; Muyzer and

373 Stams 2008) while the sulphate reducing bacteria are able to grow in soils with a large range 374 of acidity, i.e., from extremely low pH of 2 to a $\mathrm{pH}$ of 10 (Muyzer and Stams 2008).

375 The existence of the aerobic bacteria Bacillus, which require oxygen for their 376 consumption of organic matter, indicates a higher concentration of oxygen in the surface 377 layer of saturated soil, which in fact agrees with the ORP test (Fig. 9b). As well as those 378 bacteria, the Ruminococcaceae is also considerable with $8.1 \%$ but still much less than their 379 concentration at deeper layers. The predominance of the cellulose degrading bacteria in the 380 surface soils discussed above clarifies why jute, with more than $80 \%$ cellulose, decayed much 381 faster near the surface than samples buried deeper in the soil.

Although there was a large component of bacteria such as the sulphate reducing 383 groups (i.e., the Deltaproteobacteria) which can decompose the organic compounds in soils 2 384 and 3, the jute fibres in these soils did not decay very much. This was because these bacteria 385 are usually able to consume monomers such as glucose, acetate, organic acid (Barton and 386 Hamilton 2007; Muyzer and Stams 2008), whereas cellulose (the major component of natural 387 fibres such as jute) is a macromolecule (polysaccharide) which is composed of the basic unit 388 glucose (Leschine 1995). Cellulose and other carbohydrates need fermenting and breaking 389 into monomers by particular microorganisms such as many species of the Ruminococaceae, 390 Clostridium and Bacillus before they can be consumed by other microbes such as sulphate 391 reducing bacteria (Leschine 1995; Muyzer and Stams 2008). In soils 2 and 3, there was a 392 paucity of microbes that can secrete enzymes to decompose cellulose into the fundamental 393 substrates (i.e., glucose), so that even though there was a large amount of bacteria, such as 394 sulphate reducing bacteria which can consume organic matter, jute in these soils did not 395 decay much. 
Coir has a large amount of lignin, i.e., 40\% (Gupta 2011) which is a highly complex

397 heteropolymer that makes the fibre highly resistant to biodegradation compared to

398 carbohydrates such as cellulose and hemicellulose. In this fibre, lignin is bonded tightly with

399 hemicellulose and cellulose fibrils to create a stiff composite (Jayabal et al. 2012). There is a

400 significant limitation of current studies addressing lignin degrading bacteria, as reviewed by

401 Bugg et al. (2011) and Brown and Change (2014). Most degradations of lignin observed in

402 previous studies are induced by the ligninolytic enzyme activities of fungi, whereas only a

403 few soil bacteria (i.e., Actinomycetes) can decompose this complex component (Kirby 2005;

404 Fernandes et al. 2011; Brown and Chang 2014). Moreover, the degradation of lignin by

405 bacteria is found much less effective than degradation by fungi (Dashtban et al. 2010; Brown

406 and Chang 2014), which usually require a high concentration of oxygen (Cookson 1995;

407 Inglett et al. 2005; Kato et al. 2015). This explains why the coir buried in saturated soils

408 where the supply of oxygen is limited, had a very low rate of degradation.

\section{Influence of biodegradation on soil consolidation}

410 Vertical drains are normally expected to discharge excess pore pressure until the

411 design target of consolidation is achieved (Fig. 12) as usually assumed in conventional

412 approaches (Barron 1948; Hansbo 1981; Indraratna et al. 2005; Rujikiatkamjorn and

413 Indraratna 2006), but the biodegradation of a natural prefabricated vertical drain (NPVD) can

414 be very serious when exposed to an adverse environment where cellulose-degrading bacteria

415 live, as shown above. This rapid degradation of natural fibres (i.e., jute) deteriorates the

416 porous structure of drains (Fig. 7) and reduces the resistance of drains to confining pressure,

417 which can then lead to a reduction in discharge capacity of drains. With respect to the results

418 obtained through the laboratory investigation carried out in this study and previous works

419 (Miura et al. 1995; Kim and Cho 2008) which also report serious degradation of NPVDs, the 
420 influence of drain biodegradation is apparent and needs an urgent evaluation.

421 Evaluating the influence of drain biodegradation on soil consolidation

In a preliminary study without any experimental data, Indraratna et al. (2016)

423 considered the effect of drain degradation on the consolidation of soil by incorporating the

424 time-dependent function of drain discharge capacity $q_{w}(t)$ into the dissipation of excess pore

425 pressure. According to this approach, the general solution describing the radial consolidation

426 of a unit cell with respect to the biodegradation of the drain is given by:

$$
\frac{u(t)}{u_{o}}=\exp \left(-\int_{0}^{t} \frac{1}{f(t)} d t\right)
$$

427 In the above, $u_{o}$ is the initial excess pore pressure, and $f(t)$ is written as:

$$
f(t)=\chi\left(\mu_{n, s}+\frac{\lambda}{q_{w}(t)}\right)
$$

428 where $\mu_{n, s}$ is the parameter representing the effect of geometry (i.e., the size of smear and 429 influence zones), and is estimated as follows:

$$
\begin{gathered}
\mu_{n, s}=\frac{n^{2}}{n^{2}-1}\left[\ln \left(\frac{n}{s}\right)+\frac{k_{h}}{k_{s}} \ln (s)-\frac{3}{4}\right]+\frac{s^{2}}{n^{2}-1}\left[1-\frac{s^{2}}{4 n^{2}}\right] \\
+\frac{k_{h}}{k_{s}}\left(\frac{1}{n^{2}-1}\right)\left[\frac{s^{4}-1}{4 n^{2}}-s^{2}+1\right]
\end{gathered}
$$

431 In the above $n=r_{e} / r_{w} ; s=r_{s} / r_{w}$ where $r_{e}, r_{s}$ and $r_{w}$ are the radius of the influence, smear and

432 well zones, respectively; $k_{h}$ and $k_{s}$ are the coefficients of permeability in the undisturbed and

433 smear zones, respectively; $\lambda=\left(2 \pi k_{h} l^{2}\right) / 3 ; \chi=d_{e}^{2} /\left(8 c_{h}\right)$ where $c_{h}$ is the consolidation

434 coefficient for horizontal drainage; $l$ is the length of drain, and $d_{e}$ is the equivalent diameter 435 of the drain. 
437 radial consolidation of soil, the following important assumptions are also included: $(i)$ the 438 geometric parameters (i.e., equivalent diameter and length) of the drain is constant while its 439 discharge capacity decreases over time; (ii) degradation is uniform over the depth of 440 installation; and (iii) the reduced discharge capacity reaches a limit level at which the jute 441 fibres are completely absorbed into the organic components of the soil.

442 To obtain an exact solution for Eq. [1], a specific form of the degradation function $443 q_{w}(t)$ is needed. Indraratna et al. (2016), with reference to biological studies where the 444 environmental conditions are different from those of saturated soil, assumed that the 445 reduction of drain discharge capacity due to its biodegradation commences immediately after 446 the NPVDs are installed into the soil, in accordance with an exponential degradation of the 447 drain discharge capacity, as follows:

$$
q_{w}(t)=q_{w o} e^{-\omega t}
$$

448 where $\omega$ is the decay coefficient and $q_{w o}$ is the initial discharge capacity of the drain.

449 Substituting Eq. [4] in Eq. [1] and integrating yield:

$$
\frac{u(t)}{u_{o}}=\exp \left[\frac{-8 T_{h, a}}{\mu_{n, s, a}}+\frac{1}{\chi_{a} \mu_{n, s, a} \omega} \ln \left(\frac{\frac{\mu_{n, s, a}}{\mu_{q o, a}}+e^{\omega t}}{\frac{\mu_{n, s, a}}{\mu_{q o, a}}+1}\right)\right]
$$

450 The above expression is the exact solution for the radial consolidation of soil assuming a 451 mere exponential degradation of the drain discharge capacity. However, the decrease in the

452 discharge capacity of the drain in the field can be more complicated due to the following 453 reasons:

454 a) Natural fibres do not usually decay immediately after drains are installed into soil, as shown in the laboratory investigation of this study (Fig. 5 and Fig. 6), particularly in anaerobic conditions, because bacteria take time to colonise and consume organic 
matter (Inglett et al. 2005). This intact or inactive period can vary with different environmental conditions such as acidity and/or temperature, and loading process.

459 b) The degradation of a drain is not uniform over the depth of installation because the

c) In addition to biodegradation which relies basically on the activity of microorganisms

originally proposed by Indraratna et al. (2016) which only consider exponential reduction in capacity testing in the current study show a complex reduction behaviour (Fig. 6a) which is composed of different degradation forms over time. Therefore, in lieu of the exponential form 
482 of Equation [4], a general polynomial degradation form that includes convex, concave and 483 linear degradation curves, is considered as follows:

$$
q_{w}(t)=q_{w o}\left(1-a t^{b}\right)
$$

484 where $a$ is the decay coefficient that represents the rate of degradation of the drain discharge

485 capacity; and $b$ is the order of the polynomial degradation curve. Clearly $a$ and $b$ should 486 satisfy the condition: $0<\left(1-a t^{b}\right)<1$. When $b<1$, the form of degradation becomes a 487 convex function, while a concave curve emerges when $b>1$, and $b=1$ represents the linear 488 reduction of discharge capacity over time. Note that the mathematical extension presented in 489 this paper is based on the approach proposed by Indraratna et al. (2016) with respect to 490 following assumptions: (i) the discharge capacity of drains degrades over time while other 491 parameters, i.e., the diameter and length of drains are relatively unchanged; (ii) natural fibres 492 finally turn into organic components of soil, and this biodegradation combined with other 493 factors, i.e., deformation and clogging in the field results in a time-dependent reduction in 494 discharge capacity of drains.

495 Replacing Eq. [6] into Eq. [1] and re-arranging yield:

$$
\frac{u(t)}{u_{o}}=\exp \left\{-\int_{0}^{t} \frac{d t}{\chi\left[\mu_{n, s}+\frac{\chi}{q_{w o}\left(1-a t^{b}\right)}\right]}\right\}
$$

496 Several specific values of $a$ and $b$ are considered, as follows:

497 (i) Convex form: $b=0.5 ; q_{w}(t)=q_{w o}(1-a \sqrt{t})$

$$
\frac{u(t)}{u_{o}}=\exp \left[\frac{-8 T_{h}}{\mu_{n, s}}-\frac{2 \mu_{q o}}{\chi a \mu_{n, s}^{2}}\left(\sqrt{t}+\frac{\mu}{a \mu_{n, s}} \ln \left(1-\frac{\mu_{n, s} a \sqrt{t}}{\mu}\right)\right)\right]
$$

498 (ii) Concave form: $b=2 ; q_{w}(t)=q_{w o}\left(1-a t^{2}\right)$ 


$$
\begin{aligned}
\frac{u(t)}{u_{o}}=\exp \left\{\frac{-8 T_{h}}{\mu_{n, s}}\right. & \\
& +\frac{\mu_{q o}}{2 \chi \mu_{n, s} \sqrt{\mu \mu_{n, s} a}}\left[\ln \left(\sqrt{\mu}+\sqrt{\mu_{n s} a} t\right)\right. \\
& \left.\left.-\ln \left(\sqrt{\mu}-\sqrt{\mu_{n s} a} t\right)\right]\right\}
\end{aligned}
$$

499 (iii) Linear form: $b=1 ; q_{w}(t)=q_{w o}(1-a t)$

$$
\frac{u(t)}{u_{o}}=\exp \left[\frac{-8 T_{h}}{\mu_{n, s}}-\ln \left(1-\frac{\mu_{n, s} a q_{w o} t}{\left(\mu_{n, s} q_{w o}+\lambda\right)}\right)\left(\frac{\lambda}{\chi \mu_{n, s}^{2} a q_{w o}}\right)\right]
$$

500 In the above, $T_{h}$ is the time factor for horizontal drainage. $\mu=\mu_{q o}+\mu_{n, s}$ where $\mu_{q o}=$ $501\left(2 \pi k_{h} l^{2}\right) /\left(3 q_{w o}\right)$ represents the discharge capacity of the drain at its initial stage. By 502 providing these solutions for different orders of polynomial degradation curves, the complex 503 behaviour associated with the reasons $a$ and $c$ as discussed earlier can then be captured in the 504 revised model.

505 It is interesting to note that when $a$ approaches zero (no degradation of the drain), the 506 solutions presented above all approach the conventional solution proposed by Hansbo (1981).

507 For example with linear degradation $b=1$ :

$$
\lim _{a \rightarrow 0}\left\{\ln \left(1-\frac{\mu_{n, s} a q_{w o} t}{\left(\mu_{n, s} q_{w o}+\lambda\right)}\right)\left(\frac{\lambda}{\chi \mu_{n, s}^{2} a q_{w o}}\right)\right\}=\frac{\mu_{q o} t}{\chi \mu_{n, s}\left(\mu_{n, s}+\mu_{q o}\right)}
$$

508 Replacing Eq. [11] into Eq. [10] and re-arranging the result in Hansbo's solution, that is:

$$
\frac{u(t)}{u_{o}}=\exp \left(\frac{-8 T_{h}}{\mu}\right)
$$

The consolidation of soil, including different forms of drain degradation, is given by

510 accumulating the dissipation of excess pore pressure over $n$ individual stages corresponding 511 to varying forms of $q_{w i}(t)$, as follows: 


$$
u(t)=-\sum_{i=1}^{n} u_{0 i} \exp \int_{t_{i 0}}^{t_{i j}} \frac{1}{f_{i}(t)} d t
$$

512 where $f_{i}(t)$ is the function $f(t)$ shown in Eq. [2] in stage $i$, where the reduction of the discharge

513 capacity is described by the function $q_{w i}(t)$ from $t_{i 0}$ to $t_{i j} \cdot u_{0 i}$ is the initial excess pore

514 pressure of stage $i$. For different forms of $q_{w i}(t)$, i.e., the polynomial or exponential curves,

515 corresponding solutions to capture the dissipation of excess pore water pressure are used.

516 Clearly the total investigated time $t=\sum_{i=1}^{n}\left(t_{i j}-t_{i 0}\right)$. By this approach, the complex

517 degradation characteristics of jute drains as pointed out earlier (i.e. reasons $a, b$ and $c$ ) can be 518 incorporated in the time-dependent soil consolidation.

519 Prediction of soil consolidation considering various forms of degradation

520 In this section, because of the absence of sufficient field data, specific values of the

521 soil parameters and degradation properties of drains are assumed to demonstrate the proposed

522 solution for predicting the consolidation of soil. The consolidation coefficient is assumed to

523 be $0.004 \mathrm{~m}^{2} /$ year. Because previous practices indicate that NPVDs can be installed by the 524 conventional method using the same mandrel, the smear effect of NPVDs can be evaluated 525 by referring to previous studies (Indraratna and Redana 1998) of conventional synthetic 526 PVDs. The ratio $d_{s} / d_{w}$ of 3.4 is used in this paper, and the space $(S)$ and length $(l)$ of the 527 drains are $0.85 \mathrm{~m}$ and $20 \mathrm{~m}$, respectively. The horizontal permeability coefficient of $9 \times 10^{-10}$ $528 \mathrm{~m} / \mathrm{s}$ is adopted. An initial discharge capacity of $0.43 \mathrm{~m}^{3} /$ day was obtained by carrying out a 529 discharge capacity test on a non-degraded PVJD.

530 Predictions made assuming the same final (zero) discharge capacity of the drains but 531 with different forms of the degradation curve, viz., exponential, convex $(b=0.5)$, concave $(b$ $532=2)$, and linear $(b=1)$ reductions, as well as the conventional approach assuming constant 533 discharge, $q_{w}$, are shown in Fig. 13a. While the exponential and convex degradations show a 
534 rapid reduction at the beginning and become slower at the end of the investigation, the 535 concave curve represents the opposite trend, responding slowly in the first days and then 536 increasing in the later stages.

537 When the discharge capacity of the drains is subjected to different forms of 538 degradation, the pore pressure dissipation and soil consolidation varies accordingly, as shown 539 in Fig. 13b. The exponential degradation $\left(\omega=0.008\right.$ day $\left.^{-1}\right)$ of the discharge capacity is the 540 most serious case, and it causes the earliest retardation and the highest residual excess pore 541 pressure (approximately 23\%) after 500 days. Although the polynomial degradation with $b=$ 5420.5 begins to decrease at about the same rate initially as the exponential one, it slows 543 significantly after the first 100 days, leading to a less severe retardation of the pore pressure 544 dissipation curve. The concave reduction of the discharge capacity $(b=2)$, which is almost 545 insignificant for the first 150 days, gradually accelerates towards the end of the investigation 546 period and results in the least severe obstruction of excess pore pressure dissipation. The 547 linear $(b=1)$ degradation represents a slightly bigger retardation of excess pore pressure than 548 the quadratic reduction $(b=2)$ but it is still smaller than the exponential degradation. 549 Compared to the case of constant discharge capacity, the dissipation of excess pore pressure 550 is generally retarded, as expected, for all cases that assume a decrease in the drain discharge 551 capacity with time. For example, with an exponential degradation, i.e., the case with the most 552 severe reduction of discharge capacity at the beginning of the period under investigation, the 553 dissipation of $u$ after 500 days is about $10 \%$ less than the case assuming a constant $q_{w}$ curve.

554 One application of the solution obtained by combining various forms of drain 555 degradation over time is shown in Fig. 14. In this investigation (Fig. 14a), different reduction 556 behaviours of the discharge capacity are assumed in addition to the conventional approach 557 (constant $q_{w}$ ), as follows:

558 (c.l) An exponential degradation with $\omega=0.008$ day $^{-1}$ occurs immediately after the drain is 
installed (no delay time).

560 (c.2) An initial delay (intact) period of 70 days where $q_{w}$ remains constant is followed by an exponential degradation with $\omega=0.0089 \mathrm{day}^{-1}$ for the rest of the investigation period.

562 (c.3) An initial delay period of 20 days is followed by a concave polynomial $\left(a=2 \times 10^{-5}\right.$ day $^{-2}$ and $b=2$ ) and this is followed by an exponential degradation with $\omega=0.00913$ day $^{-1}$. Compared to case (c.2), a transition period of 80 days (with polynomial degradation) is added.

567 Although the discharge capacity test in this study has shown an intact period from 100 to 150 days, Kim and Cho (2008) presents an earlier start of the reduction through their laboratory test, indicating a complex reduction behaviour in discharge capacity of natural fibre drains.

570 This section hence assumes an intact period less than 100 days to demonstrate how the 571 analytical model can capture the corresponding soil behaviour. Case (c.l) represents a single 572 form of degradation (exponential) while cases (c.2) and (c.3) show a combination of multiple 573 forms of $q_{w}$ degradation over time, which is probably more realistic. The consolidation of the 574 soil in case (c.l) is predicted by Eq. [5] for the purely exponential degradation of the drain, 575 whereas for the multi-form degradation, Eq. [13], incorporating solutions for conventional, 576 polynomial $(b=2)$ and exponential degradation, is used.

Fig. 14b shows how the consolidation induced by a single form differs from one 578 induced by a multiple-form of degradation. Case (c.l) has the earliest degradation that results 579 in the highest residual excess pore pressure after 500 days while the combined reduction 580 forms, i.e., cases (c.2) and (c.3), which have $q_{w}$ decreasing after an initial delay stage, do not 581 obstruct the dissipation of excess pore pressure very much. Case (c.2) having the initial 70 582 days without any degradation, followed by an exponential reduction, has the consolidation 583 curve retarded slightly more severely than case (c.3) where the intact period of the drain is 
584 shorter (i.e., 20 days) but the rate of degradation in the exponential reduction stage is higher

$585\left(\omega=0.00913\right.$ day $\left.^{-1}\right)$.

586 Model Limitations

Although the analytical model proposed in this paper has shown a certain success in 588 capturing the influence of drain degradation on soil consolidation, it has not been validated 589 properly with consolidation data particularly in the field. Because this is an evolving area in 590 bio-geomechanical research where there is a significant lack of understanding, more studies 591 addressing this area particularly in the field is essential.

\section{Conclusions}

A laboratory investigation where samples of Prefabricated Vertical Jute Drain were

594 installed in saturated soft soil with different levels of acidity was carried out. In this study, 595 reductions in the tensile strength and discharge capacity of fibre drains were recorded over 596 time and a genetic analysis of the decayed fibres was implemented to identify the microbial 597 properties of the medium. Based on these laboratory results, an analytical method to predict 598 the consolidation behaviour of soil incorporating the biodegradation of natural fibre drains 599 was proposed, and the following conclusions can be drawn.

600 1. Coir having a major component of lignin retained more than $80 \%$ of its original tensile 601 strength after more than 600 days exposed to saturated soil, indicating an outstanding 602 resistance to biodegradation, exceeding the performance of jute which lost around $85 \%$ its 603 fresh strength after 300 days buried in neutral conditions. No particular lignin degrading 604 microorganisms were found in all soils investigated.

605 2. Discharge capacity of fibre drains buried in soil 1 did not decrease significantly at low 606 confining pressure however it begun to decrease considerably as the confining pressure 607 increased. After 300 days exposed in soil 1, the discharge capacity of drains reduced from 
$608 \quad 0.26$ and $0.19 \mathrm{~m}^{3} /$ day to 0.05 and $0.025 \mathrm{~m}^{3} /$ day under 50 and $100 \mathrm{kPa}$ confining pressure, 609 respectively. Drains buried in soil 2 and 3 did not show considerable reduction in 610 discharge capacity over the period of experimentation.

6113 . The biodegradation of jute was significantly influenced by the acidity of the medium. Soil 612 with a neutral condition resulted in the fastest decay of jute while a more acidic medium 613 (i.e., $\mathrm{pH}$ of 3.5 to 4.5 in soils 2 and 3, respectively) made biodegradation less severe 614 because the presence of cellulose-degrading bacteria, such as species of the families 615 Ruminococaceae; Bacillaceae (the genus Bacillus) and Clostridia (the genus Clostridium), 616 was reduced in the acidic soils.

617 4. The soils 2 and 3 were rich in the Alpha-, Beta- and Delta-Proteobacteria (i.e., sulphate 618 reducing bacteria), which can only decompose monomeric organic matter (e.g., glucose, 619 acetate, organic acids). In particular, they lacked the cellulose degrading bacteria 620 necessary for the effective degradation of jute and coir, which are macromolecule 621 materials. Hence there was less degradation of their fibres in soils 2 and 3 . This indicates 622 that a biological investigation into the soil present in the field should be carried before 623 using natural fibre drains, in order to clarify whether potential cellulose degrading 624 bacteria exist in the soil, thus allowing the appropriate solution involving fibre drains to 625 be selected.

626 5. An analytical approach to predict soil consolidation incorporating multiple forms of drain 627 degradation $q_{w}$ over time has been proposed. Evaluation of the solution considering an 628 initial intact period showed a deviation $(>5 \%)$ in the dissipation of excess pore pressure 629 compared to the approach using an immediate reduction of discharge capacity; suggesting 630 the consolidation of soil induced by a biodegradable drain can now be predicted more 631 realistically. 


\section{Acknowledgements}

633 The authors acknowledge the National Jute Board of India and the Australia Research

634 Council for funding this research. The genomic analyses were carried out in the Australian

635 Genome Research Faculty (AGRF). Microscopic observation on the samples was carried out

636 in the Australian Institute of Innovative Materials (AIIM), University of Wollongong. The $1^{\text {st }}$

637 author's PhD scholarship was sponsored by the Australia Endeavour Scheme.

638 


\section{REFERENCES}

640 Asha, B.S. and Mandal, J.N. 2012. Absorption and discharge capacity tests on natural prefabricated vertical drains. Geosynthetics International, 19: 263-271.

Asha, B.S. and Mandal, J.N. 2015. Laboratory performance tests on natural prefabricated vertical drains in marine clay. Ground Improvement, 168(1): 45-65.

ASTM D4716. 2008. Standard test method for constant head hydraulic transmissivity (Inplane flow) of geotextiles and geotextile related products. American Society for Testing and Materials, West Conshohocken, Pa.

Banerjee, P.K. 2012. Environmental textiles from jute and coir. In Handbook of natural fibres: Processing and applications. Edited by R. M. Kozlowski. Woodhead publishing. pp. 401-427.

Barron, R.A. 1948. The influence of drain wells on the consolidation of fine-grained soils. Trans ASCE, 113(2348): 718-54.

Barton, L.L. and Hamilton, W.A. 2007. Sulphate-reducing bacteria: Environmental and engineered systems. Cambridge University Impress.

Berg, J., Brandt, K.K., Al-Soud, W.A., Holm, P.E., Hansen, L.H., Sørensen, S.J. and Nybroe, O. 2012. Selection for Cu-Tolerant Bacterial Communities with Altered Composition, but Unaltered Richness, via Long-Term $\mathrm{Cu}$ Exposure. Applied and Environmental Microbiology, 78(20): 7438-7446. doi: 10.1128/aem.01071-12.

Biology,

19:

1-7.

doi: 
664 Bugg, T.D.H., Ahmad, M., Hardiman, E.M. and Rahmanpour, R. 2011. Pathways for degradation of lignin in bacteria and fungi. Natural Product Reports, 28(12): 18831896.

Chu, J., Bo, M.W. and Choa, V. 2004. Practical considerations for using vertical drains in soil improvement projects. Geotextiles and Geomembranes, 22(1-2): 101-117.

Cookson, J.T. 1995. Bioremediation engineering: Design and Application. McGraw Hill, New York.

Dashtban, M., Schraft, H., Syed, T.A. and Qin, W. 2010. Fungal biodegradation and enzymatic modification of lignin. International Journal of Biochemistry and Molecular Biology, 1(1): 36-50.

Defoirdt, N., Biswas, S., Vriese, L.D., Tran, L.Q.N., Acker, J.V., Ahsan, Q., Gorbatikh, L., Vuure, A.V. and Verpoest, I. 2010. Assessment of the tensile properties of coir, bamboo and jute fibre. Composites Part A, 41(5): 588-595.

Delaune, R.D. and Reddy, K.R. 2005. Anaerobic soils. In Encyclopedia of Soils in the Environment. Edited by D. Hillel. Elsevier, Oxford. pp. 366-371.

DeSantis, T.Z., Hugenholtz, P., Larsen, N., Rojas, M., Brodie, E.L., Keller, K., Huber, T., Dalevi, D., Hu, P. and Andersen, G.L. 2006. Greengenes, a Chimera-Checked 16S rRNA Gene Database and Workbench Compatible with ARB. Applied and Environmental Microbiology, 72(7): 5069-5072. doi: 10.1128/aem.03006-05.

Fernandes, N.A., Isikhuemhen, O.S. and Ohimain, E.I. 2011. Lignin degradation, ligninolytic enzymes activities and exopolysaccharide production by Grifola frondosa strains cultivated on oak sawdust. Brazilian Journal of Microbiology, 42(3): 1101-1108.

Fierer, N., Bradford, M.A. and Jackson, R.B. 2007. Toward an ecological classification of soil bacteria. Ecology, 88(6): 1354-1364. doi: 10.1890/05-1839. 
688 Goodfellow, M., Kampfer, P., Vos, P.D., Rainey, F., Schleifer, K.H., Whitman, W.B., Brenner, D.J., Castenholz, R.W., Garrity, G.M., Holt, J.G., Krieg, N.R., Liston, J., Moulder, J.W., Murray, R.G.E., Sneath, P.H.A., Staley, J.T. and Tully, J.G. 2009. Bergey's manual of systematic bacteriology. 2 ed. Vol. 3-The Firmicutes. Springer, New York.

Gregory, M.R. and Andrady, A.L. 2003. Plastic in the marine environment. In Plastics and Environment. Edited by A. L. Andrady. John Wiley \& Sons, New Jersey. pp. 379401.

Gupta, K.M. 2011. Starch based composites for packing applications. In Handbook of bioplastics and biocomposites engineering applications. Edited by S. Pilla. John Wiley \& Sons, Massachusetts.

Hansbo, S. 1981. Consolidation of fine-grained soils by prefabricated drains and lime column installation. In Proceedings of the Proceedings of 10th International Conference on Soil Mechanics and Foundation Engineering, Stockholm, A.A. Balkema, Rotterdam,

Indraratna, B. and Redana, I.W. 1998. Development of the smear zone around vertical band The Netherlands. Vol. 3, pp. 677-682.

Indraratna, B., Nguyen, T.T., Carter, J. and Rujikiatkamjorn, C. 2016. Influence of

708 Indraratna, B., Sathananthan, I., Bamunawita, C. and Balasubramaniam, A.S. 2005.

709 Theoretical and numerical perspectives and field observations for the design and

710 performance evaluation of embankments constructed on soft marine clay. In: B. Indraratna \& Chu, J. (eds.) Ground Improvement Case Histories.

712 Inglett, P.W., Reddy, K.R. and Corstanje, R. 2005. Anaerobic soils. In Encyclopedia of Soils 
714 Jang, Y.S., Kim, Y.W. and Park, J.Y. 2001. Consolidation efficiency of natural and plastic geosynthetic band drains. Geosynthetics International, 8(4): 283.

716 Jayabal, S., Sathiyamurthy, S., Loganathan, K.T. and Kalyanasundaram, S. 2012. Effect of soaking time and concentration of $\mathrm{NaOH}$ solution on mechanical properties of coirpolyester composites. Bull. Mater. Sci, 35(4): 567-574.

Kato, S., Chino, K., Kamimura, N., Masai, E., Yumoto, I. and Kamagata, Y. 2015. Methanogenic degradation of lignin-derived monoaromatic compounds by microbial enrichments from rice paddy field soil. Scientific Reports, 5: 14295.

Kim, J.H. and Cho, N. 2008. Pilot scale field test for natural fiber drain. In Proceedings of the 4th Asian Regional Conference on Geosynthetics, Edited by G. Li, Chen, Y. \& Tang,

Kirby, R. 2005. Actinomycetes and Lignin Degradation. In Advances in Applied Microbiology. Edited by J. W. B. G. M. G. Allen I. Laskin \& Sima, S. Academic Press. pp. 125-168.

Kirk, J.L., Beaudette, L.A., Hart, M., Moutoglis, P., Klironomos, J.N., Lee, H. and Trevors, J.T. 2004. Methods of studying soil microbial diversity. Journal of Microbiological

734 Lee, S.L., Karunaratne, G.P. and Aziz, M.A. 2003. Design and performance of Fibredrain in soil improvement projects. Ground Improvement, 7(4): 149-156. doi: doi:10.1680/grim.2003.7.4.149.

737 Lee, S.L., Karunaratne, G.P., Ramaswamy, S.D., Aziz, M.A. and Das Gupta, N.C. 1994. 
Natural geosynthetic drain for soil improvement. Geotextiles and Geomembranes, 13(6-7): 457-474.

740 Lee, S.L., Ramaswamy, S.D., Aziz, M.A., Das Gupta, N.C. and N. C. \& Karunaratne, G.P. 1987. Fibredrain for consolidation of soft soils. In Proceedings of the Post- Vienna

Leschine, S.B. 1995. Cellulose degradation in anaerobic environments. Annual Review of Conference on Geotextiles, Singapore. Vol. 2, pp. 238-58.

745 Liu, B.-R., Jia, G.-M., Chen, J. and Wang, G. 2006. A Review of Methods for Studying Microbial Diversity in Soils. Pedosphere, 16(1): 18-24.

Mahmoudi, N., Slater, G.F. and Fulthorpe, R.R. 2011. Comparison of commercial DNA

Miura, T., M, T., H, M. and M, B. 1995. The basic experiment on permeability characteristics

Maron, P.-A., Mougel, C. and Ranjard, L. 2011. Soil microbial diversity: Methodological extraction kits for isolation and purification of bacterial and eukaryotic DNA from PAH-contaiminated soil. Canadian Journal of Microbiology, 57(8): 623-628. strategy, spatial overview and functional interest. Comptes Rendus Biologies, 334(56): 403-411. of fibredrain. Proceeding of Annual Regional Meeting of JSCE. Kyushu (in Japanese).

MO BIO Laboratories Inc. Instruction Manual of PowerLyzer-PowerSoil DNA Isolation Kit.

762 Nguyen, T.T. and Indraratna, B. 2017a. Experimental and numerical investigations into 
hydraulic behaviour of coir fibre drain. Canadian Geotechnical Journal, 54(1): 75-87.

764 Nguyen, T.T. and Indraratna, B. 2017b. The permeability of natural fibre drains, capturing their micro-features. Proceedings of the Institution of Civil Engineers - Ground Improvement, 0(0): 1-14. doi: 10.1680/jgrim.16.00032.

767 Patel, G.B., Khan, A.W., Agnew, B.J. and Colvin, J.R. 1980. Isolation and Characterization of an Anaerobic, Cellulolytic Microorganism, Acetivibrio cellulolyticus gen. nov., sp.

Pineda, J.A., Suwal, L.P., Kelly, R.B., Bates, L. and Sloan, S.W. 2016. Characterisation of nov. $\dagger$. International Journal of Systematic and Evolutionary Microbiology, 30(1): 179-185. doi: doi:10.1099/00207713-30-1-179.

Ballina clay. Geotechnique, 66(7): 556-577.

Rahman, M.S. 2010. Jute- a versatile natural fibre. Cultivation, Extraction and Processing. In Industrial applications of natural fibres: Structure, properties and technical applications. Edited by J. Mussig. A John Wiley and Sons, Ltd, Publication, Chichester, United Kingdom. pp. 135-161.

Rousk, J., Baath, E., Brookes, P.C., Lauber, C.L., Lozupone, C., Caporaso, J.G., Knight, R. and Fierer, N. 2010. Soil bacterial and fungal communities across a $\mathrm{pH}$ gradient in an arable soil. ISME J, 4(10): 1340-1351.

Rubin, B.E.R., Gibbons, S.M., Kennedy, S., Hampton-Marcell, J., Owens, S. and Gilbert, J.A. 2013. Investigating the Impact of Storage Conditions on Microbial Community Composition in Soil Samples. PLoS ONE, 8(7): e70460. doi: 10.1371/journal.pone.0070460.

Rujikiatkamjorn, C. and Indraratna, B. 2006. Analytical solutions and design curves for vacuum-assisted consolidation with both vertical and horizontal drainage. Canadian Geotechnical Journal, 44(188-200).

Saha, P., Roy, D., Manna, S., Adhikari, B., Sen, R. and Roy, S. 2012. Durability of 
transesterified jute geotextiles. Geotextiles and Geomembranes, 35: 69-75. doi: http://dx.doi.org/10.1016/j.geotexmem.2012.07.003.

790 Singh, J., Birbian, N., Sinha, S. and Goswami, A. 2014. A critical review on PCR, its types and applications. International Journal of Advanced Research in Biological Sciences, 1(7): $65-80$.

793 Som, N., Chattopadhyay, B.C. and Sanyal, T. 2009. A manual on use of jute geotextiles in 794 civil eingieering, 4th Edition. Jute Manufactures Development Council, Kolkata, India.

796 Spectrum Technologies Int. 2011. pH Meter Product Manual Item 2162S.

797 TPS. 2012. Product Manual of pH, ORP, Temp Meter-Model WP-80D. Brisbance.

798 Trivedi, N., Gupta, V., Kumar, M., Kumari, P., C.R.K.Reddy and Jha, B. 2011. An alkali799 halotolerant cellulase from Bacillus flexus isolated from green seaweed Ulva lactuca.

$800 \quad$ Carbohydrate $\quad$ Polymers, $\quad$ 83(2): 891-897. doi:

$801 \quad$ http://dx.doi.org/10.1016/j.carbpol.2010.08.069. 


\section{LIST OF FIGURES}

806 Fig. 1 PVJD sample inserted into soft clay and $\mathrm{pH}$ measurement...................................... 39

807 Fig. 2 Tension test on: $(a)$ the whole drain; and $(b)$ individual fibre.................................... 40

808 Fig. 3 Discharge capacity test: a) schematic view; b) drain extracted from soil and wrapped

809 by membrane; and c) drain being confined by cell pressure.

810 Fig. 4 DNA analysis for decayed fibres: a) fibres extracted from saturated soil; b) fibres in

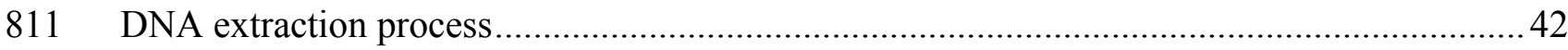

812 Fig. 5 Reduction in tensile strength: a) individual fibres: b) complete drains...................... 43

813 Fig. 6 Discharge capacity test results a) variation in discharge capacity with time and

814 confining pressure; b) drain broken after extracting from soil after 520 days. 44

815 Fig. 7 Degradation of jute under micro-observation: a) undisturbed condition; and b) after

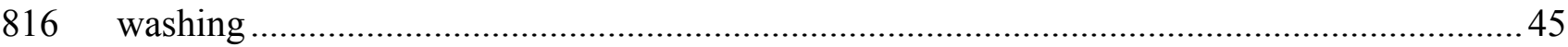

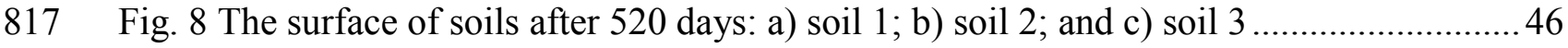

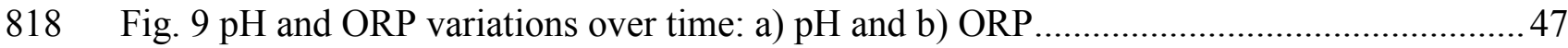

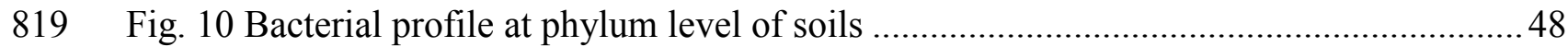

820 Fig. 11 Variation of phylum levelled bacteria over different $\mathrm{pH}$ of the medium.................. 49

821 Fig. 12 Degradation of NPVDs in relation to consolidation process of soil .........................50

822 Fig. 13 Different degradation forms of $\left.q_{w}(t): a\right)$ discharge capacity; and $b$ ) corresponding

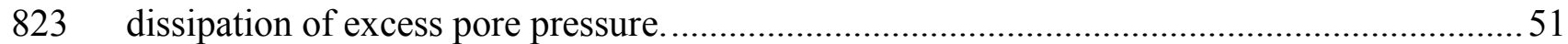

824 Fig. 14 Dissipation of excess pore pressure considering different degradation forms of 825 discharge capacity over time: $a$ ) combined different forms of degradation; $b$ ) corresponding

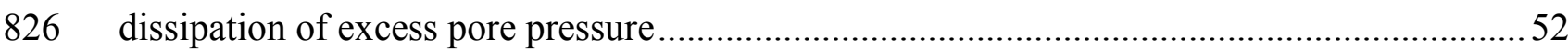


828 LIST OF FIGURES (APPENDICES)

829 Fig. A1 Bacterial community in soil/container 1 (at $40 \mathrm{~cm}$ depth) ...................................5

830 Fig. A2 Bacterial community at the surface layer of soil/container 1 (at $5 \mathrm{~cm} \mathrm{depth) \ldots \ldots .....54}$

831 Fig. A3 Bacterial community in soil/container 2 (at $40 \mathrm{~cm}$ depth) .................................. 55

832 Fig. A4 Bacterial community in soil/container 3 (at $40 \mathrm{~cm}$ depth) .....................................56

833 


\section{FIGURES}

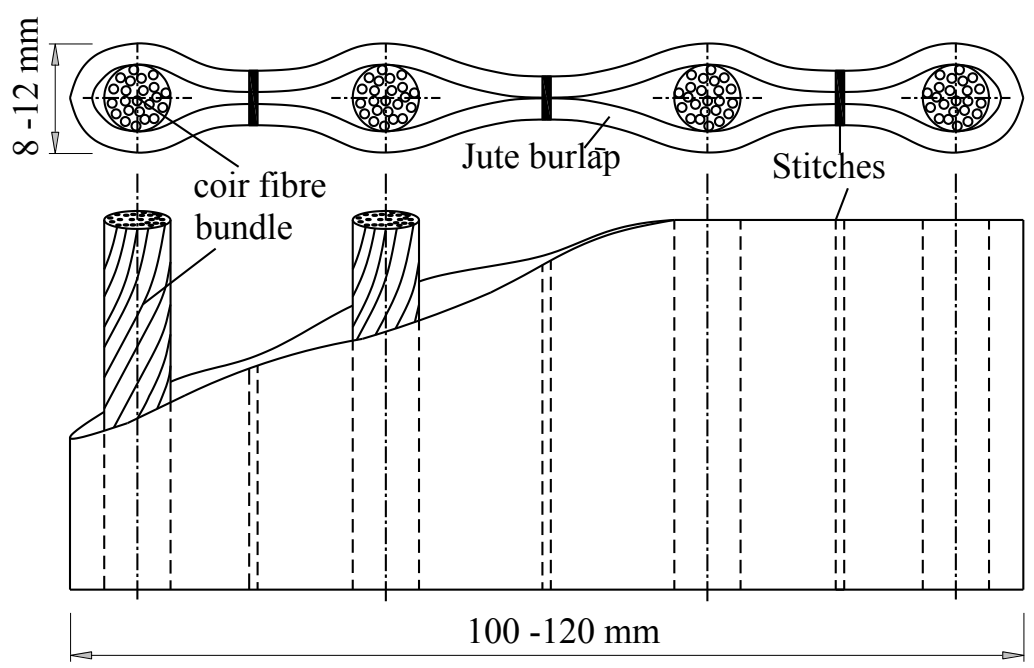

a) Structure of prefabricated vertical jute drain

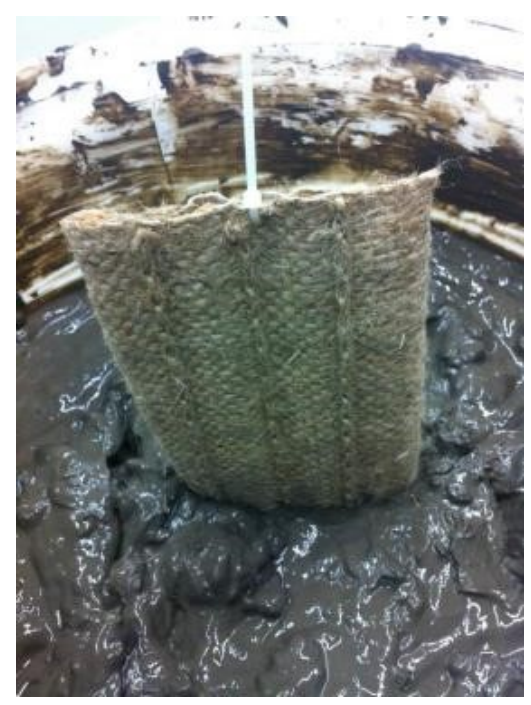

b) Drain insertion

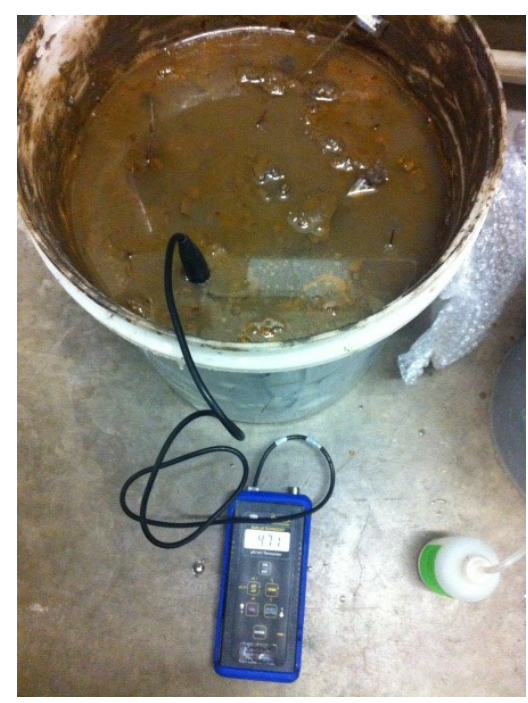

c) $\mathrm{pH}$ measurement

Fig. 1 PVJD sample inserted into soft clay and $\mathrm{pH}$ measurement 

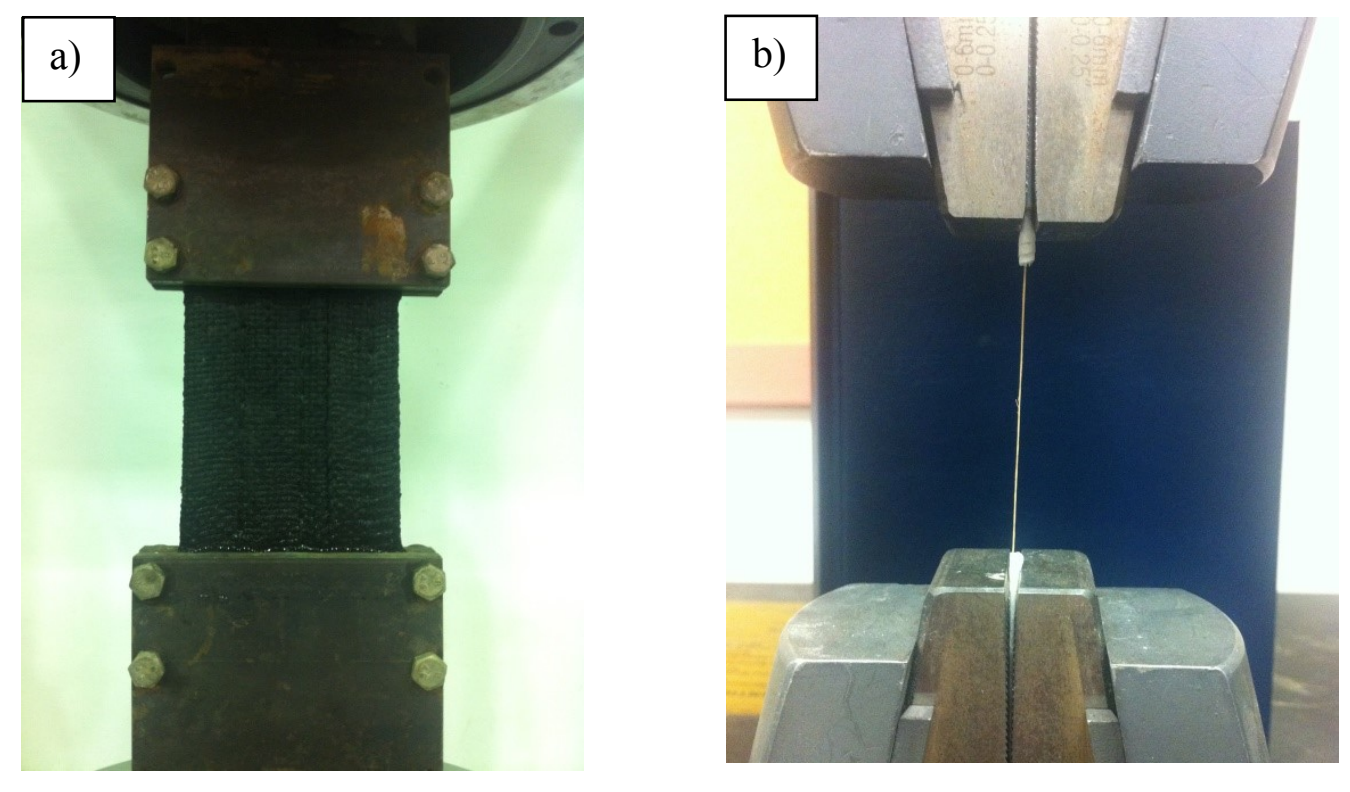

Fig. 2 Tension test on: $(a)$ the whole drain; and $(b)$ individual fibre 


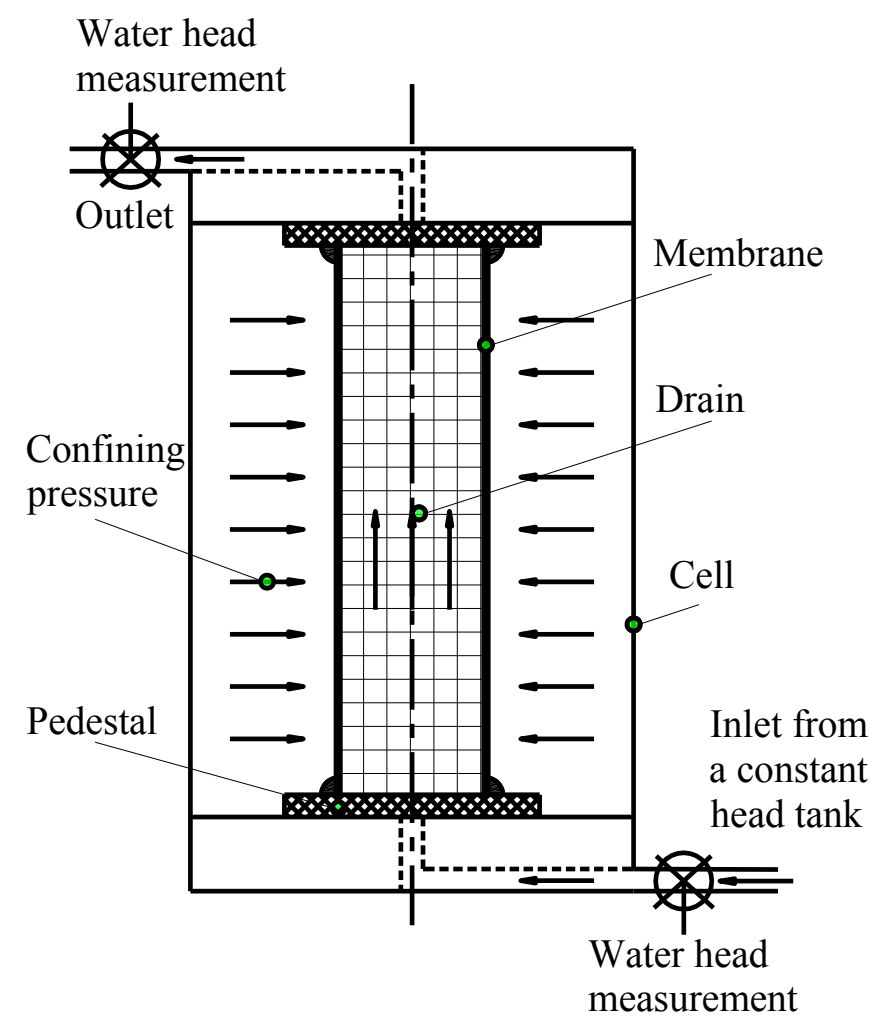

a) Schematics of discharge capacity test

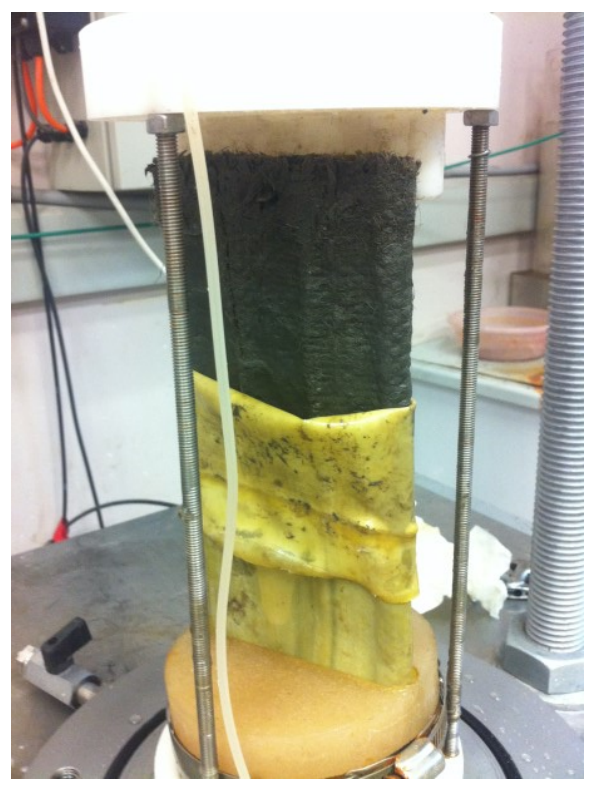

b) Drain on pedestal in the test

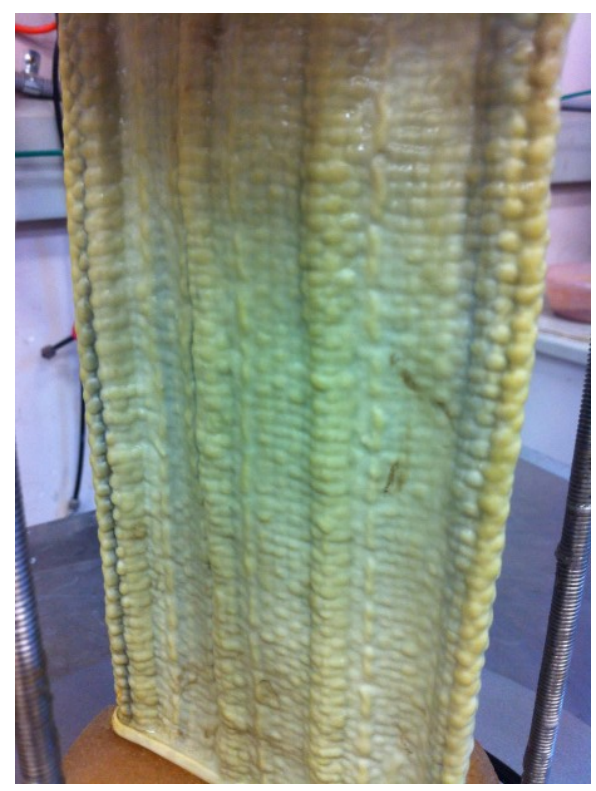

c) Drain being confined

Fig. 3 Discharge capacity test: a) schematic view; b) drain extracted from soil and wrapped by membrane; and c) drain being confined by cell pressure. 

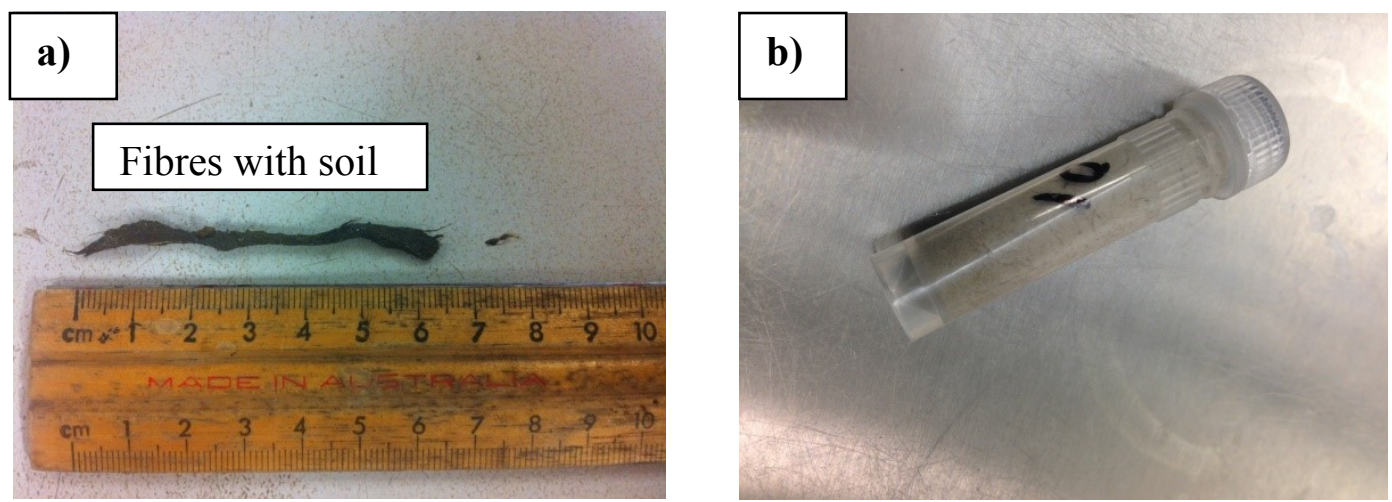

Fig. 4 DNA analysis for decayed fibres: a) fibres extracted from saturated soil; b) fibres in DNA extraction process 


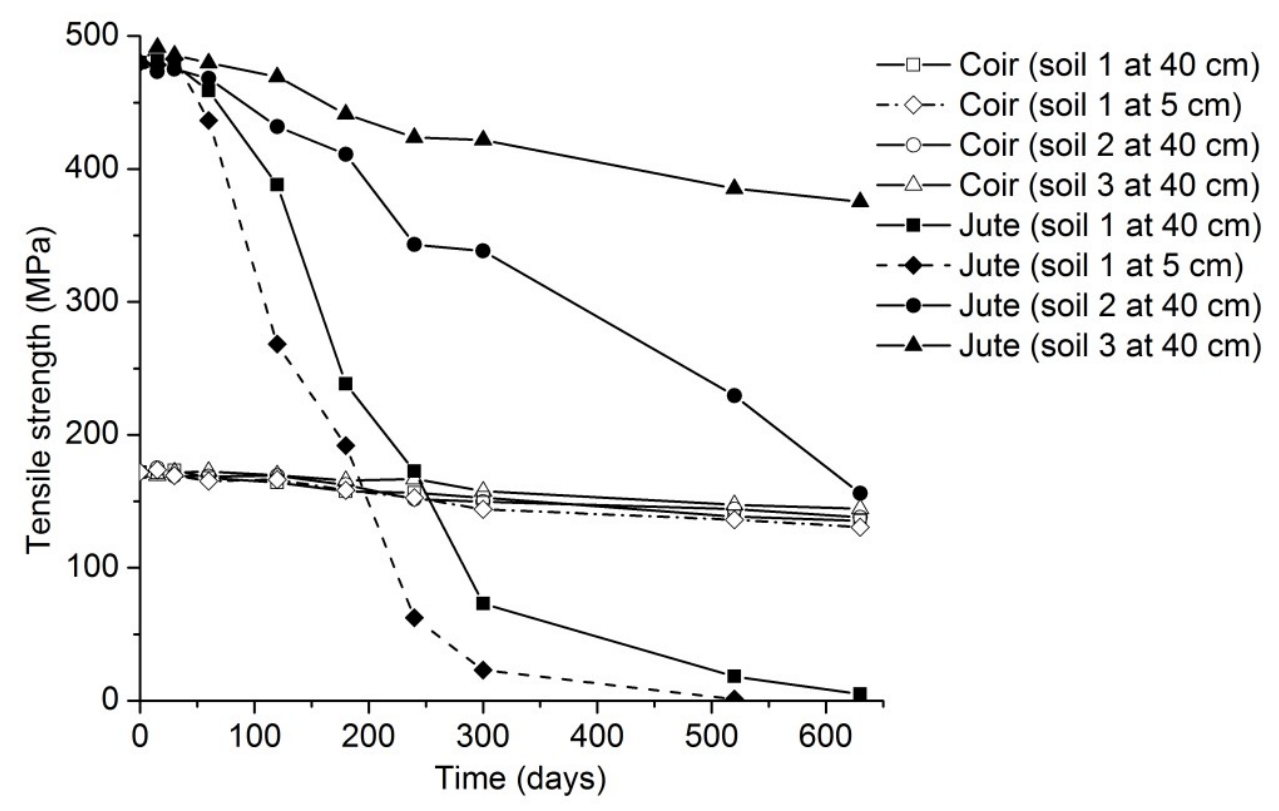

a) Individual jute and coir fibres

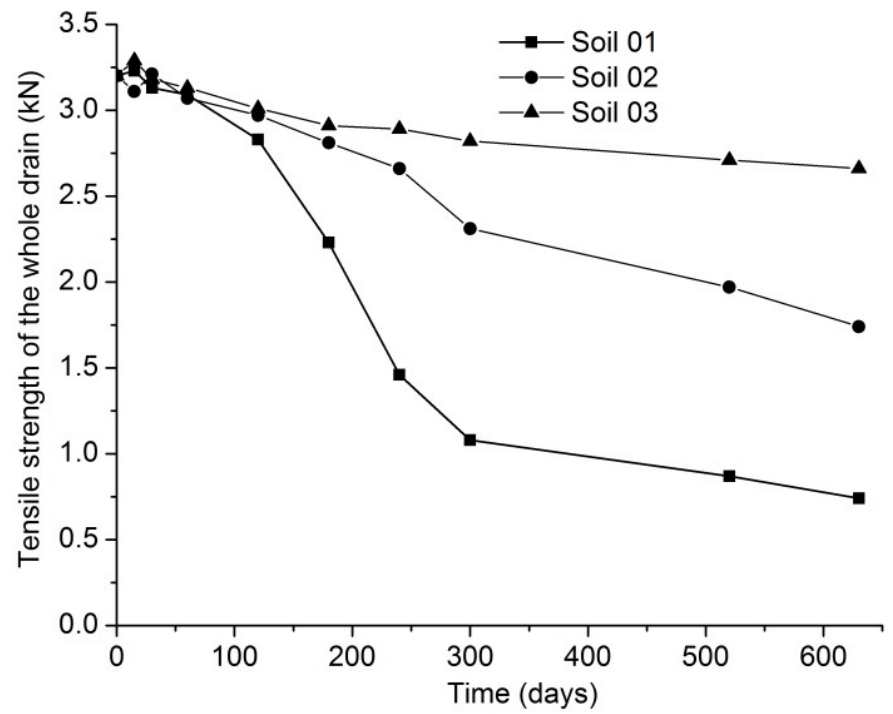

b) Complete drains

Fig. 5 Reduction in tensile strength: a) individual fibres: b) complete drains 


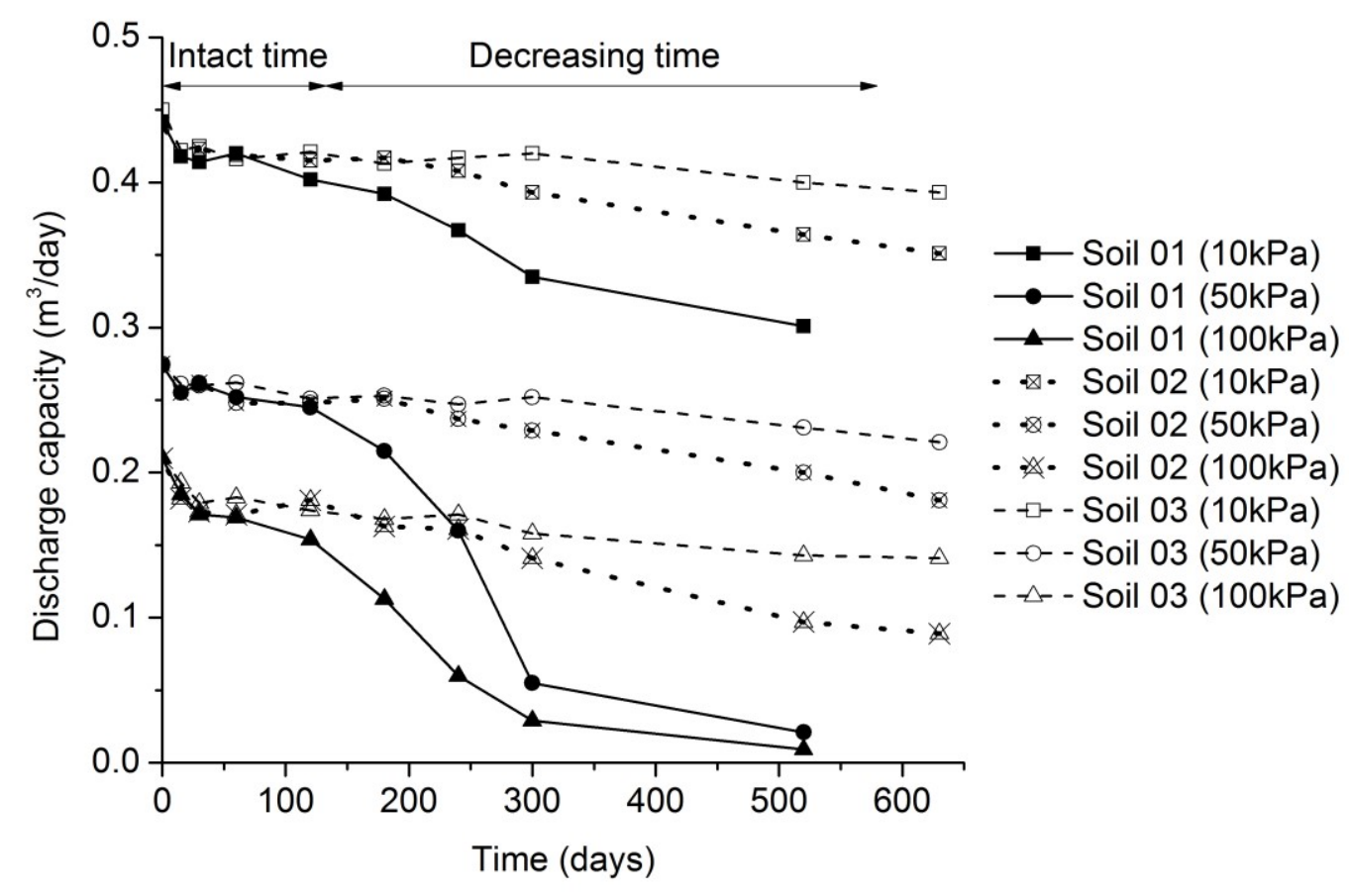

a)

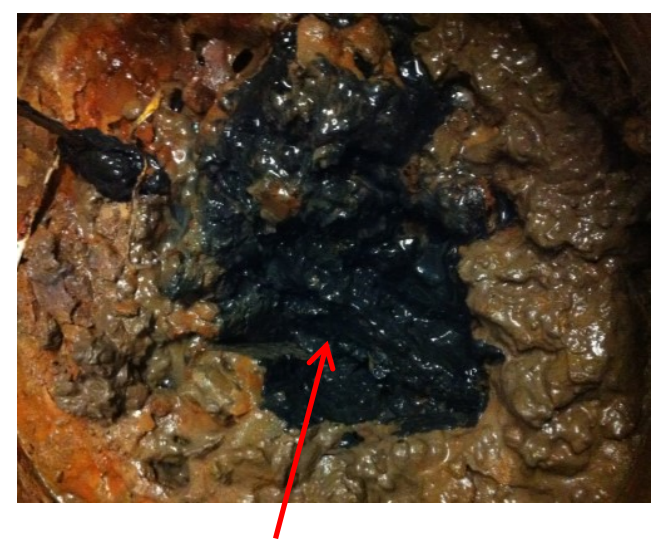

Dark compound built around drains in soil 01

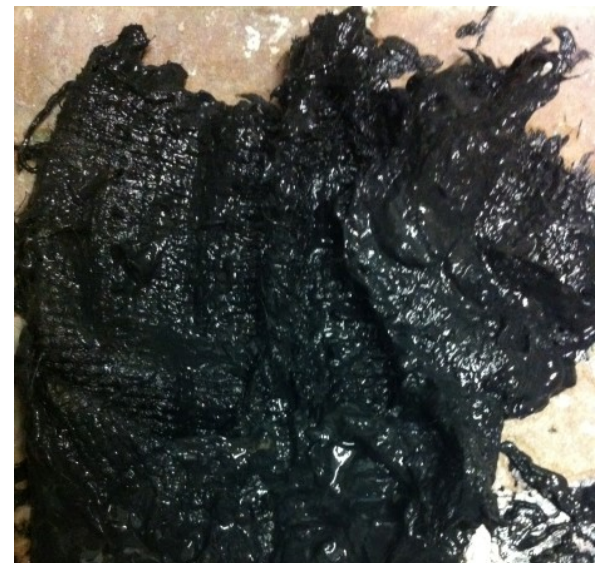

Jute filter broken after 520 days in soil 1

b)

Fig. 6 Discharge capacity test results a) variation in discharge capacity with time and confining pressure; b) drain broken after extracting from soil after 520 days. 

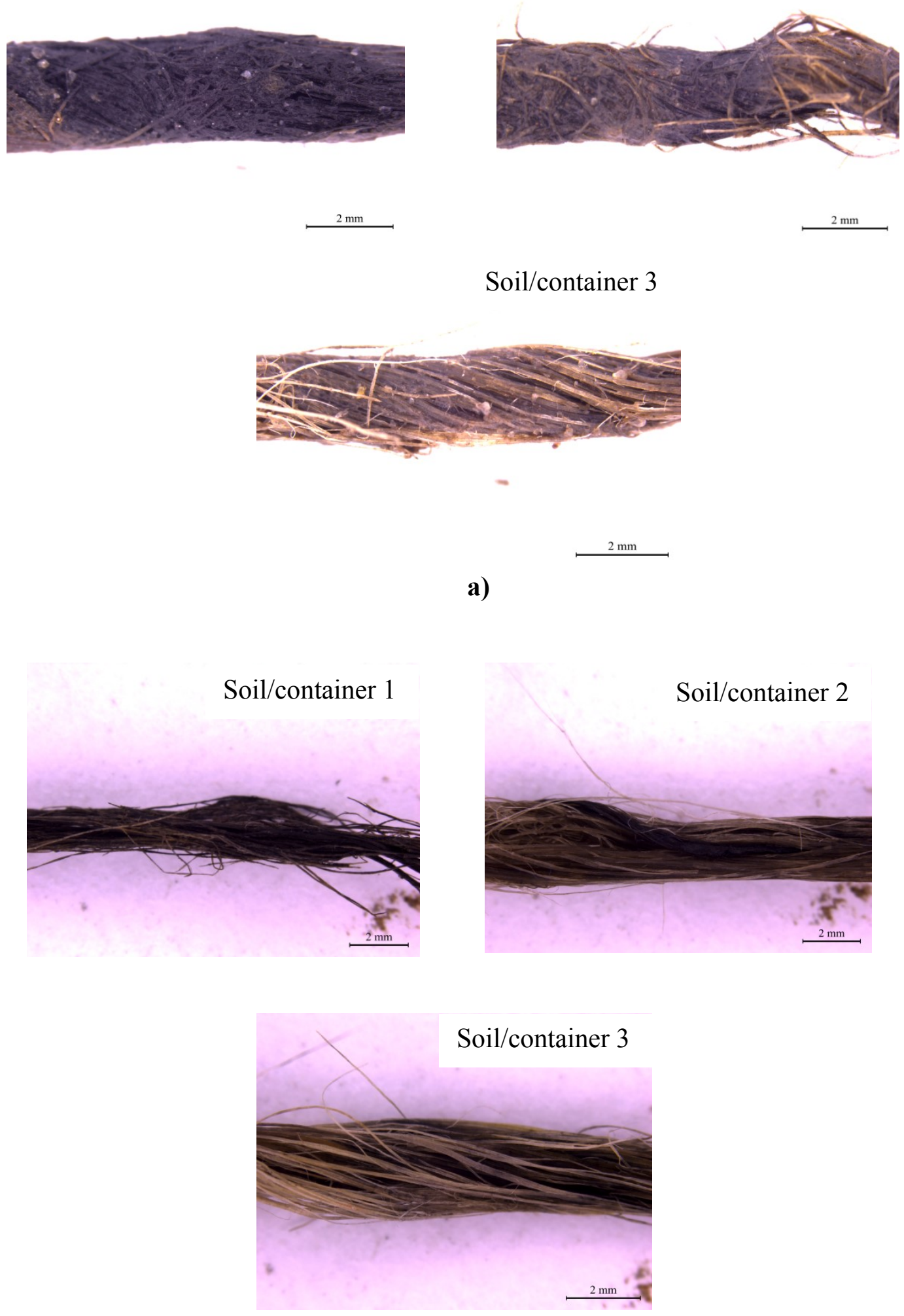

b)

Fig. 7 Degradation of jute under micro-observation: a) undisturbed condition; and b) after washing 


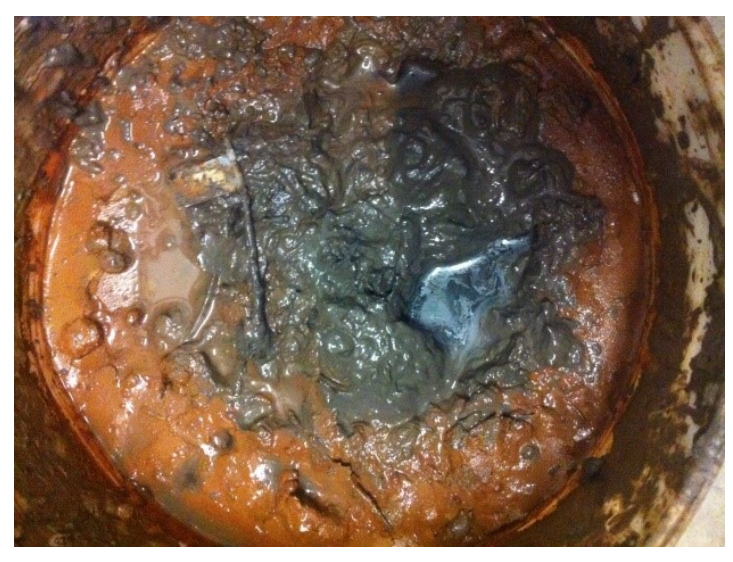

a) Soil/container 1

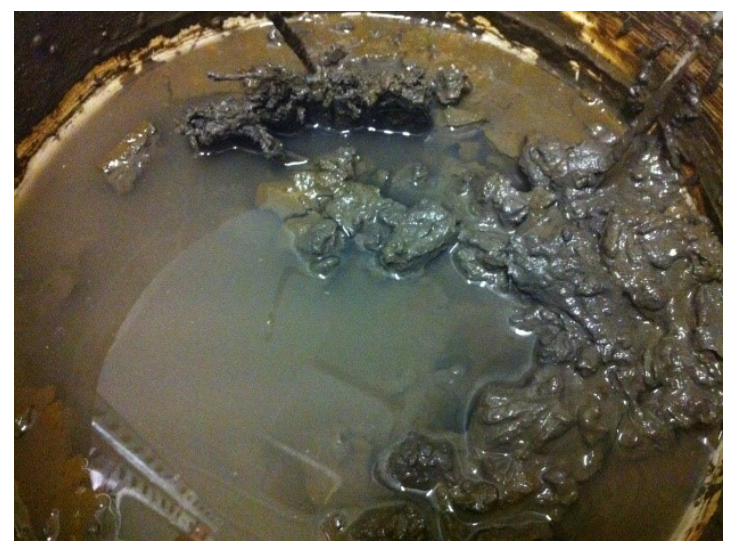

c) Soil/container 3

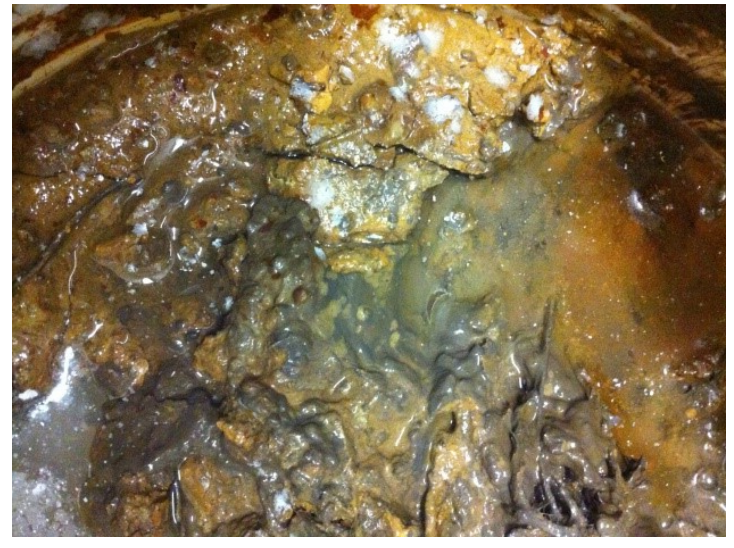

b) Soil/container 2

Fig. 8 The surface of soils after 520 days: a) soil 1; b) soil 2; and c) soil 3 


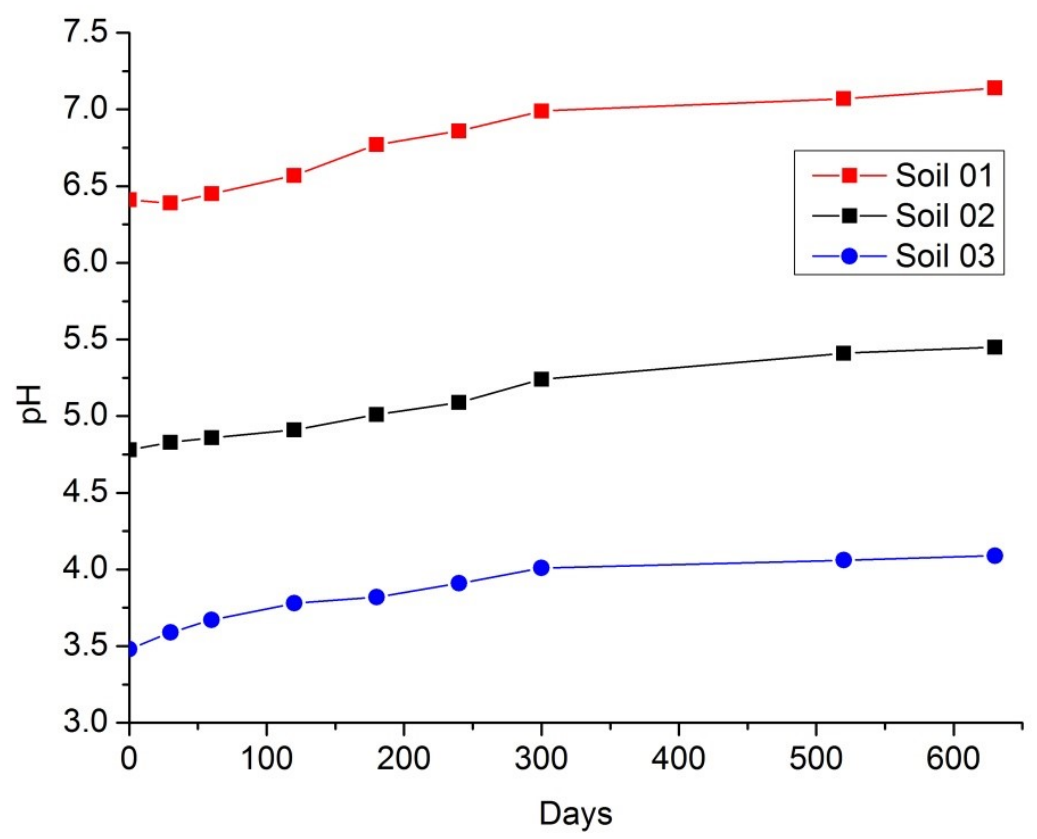

a) $\mathrm{pH}$ variation

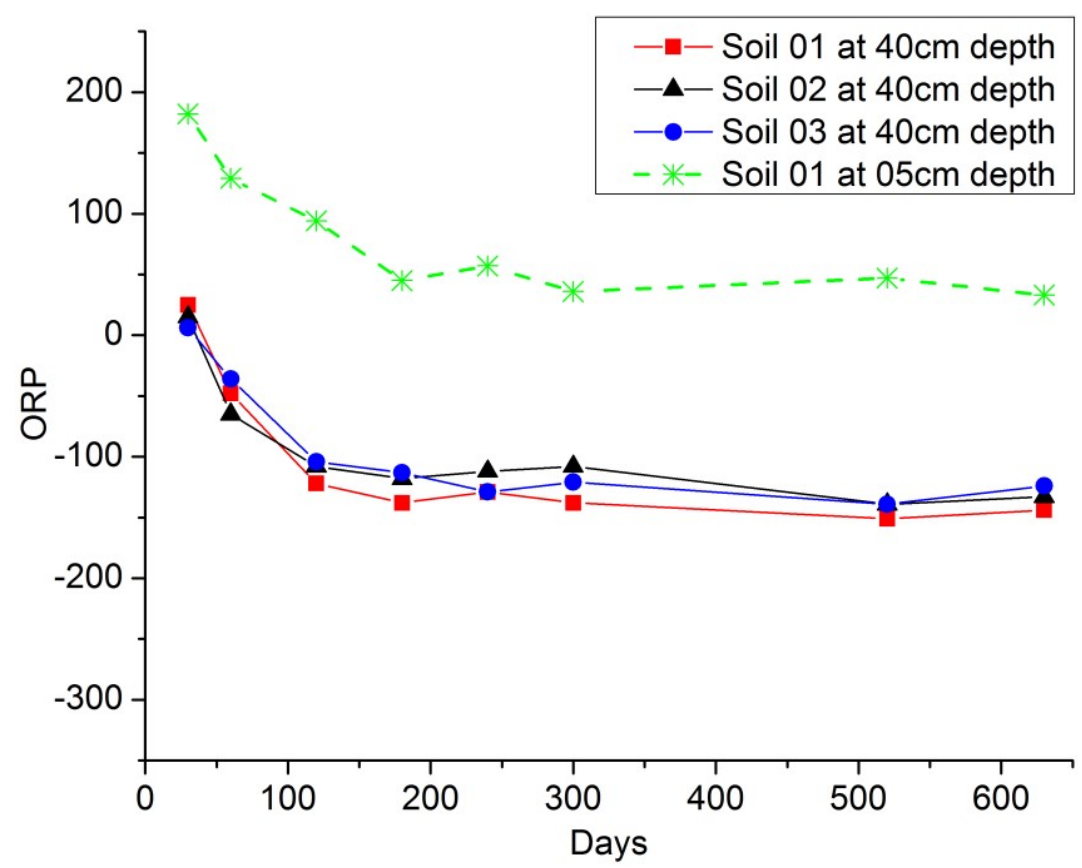

b) ORP variation

Fig. $9 \mathrm{pH}$ and ORP variations over time: a) $\mathrm{pH}$ and b) ORP 


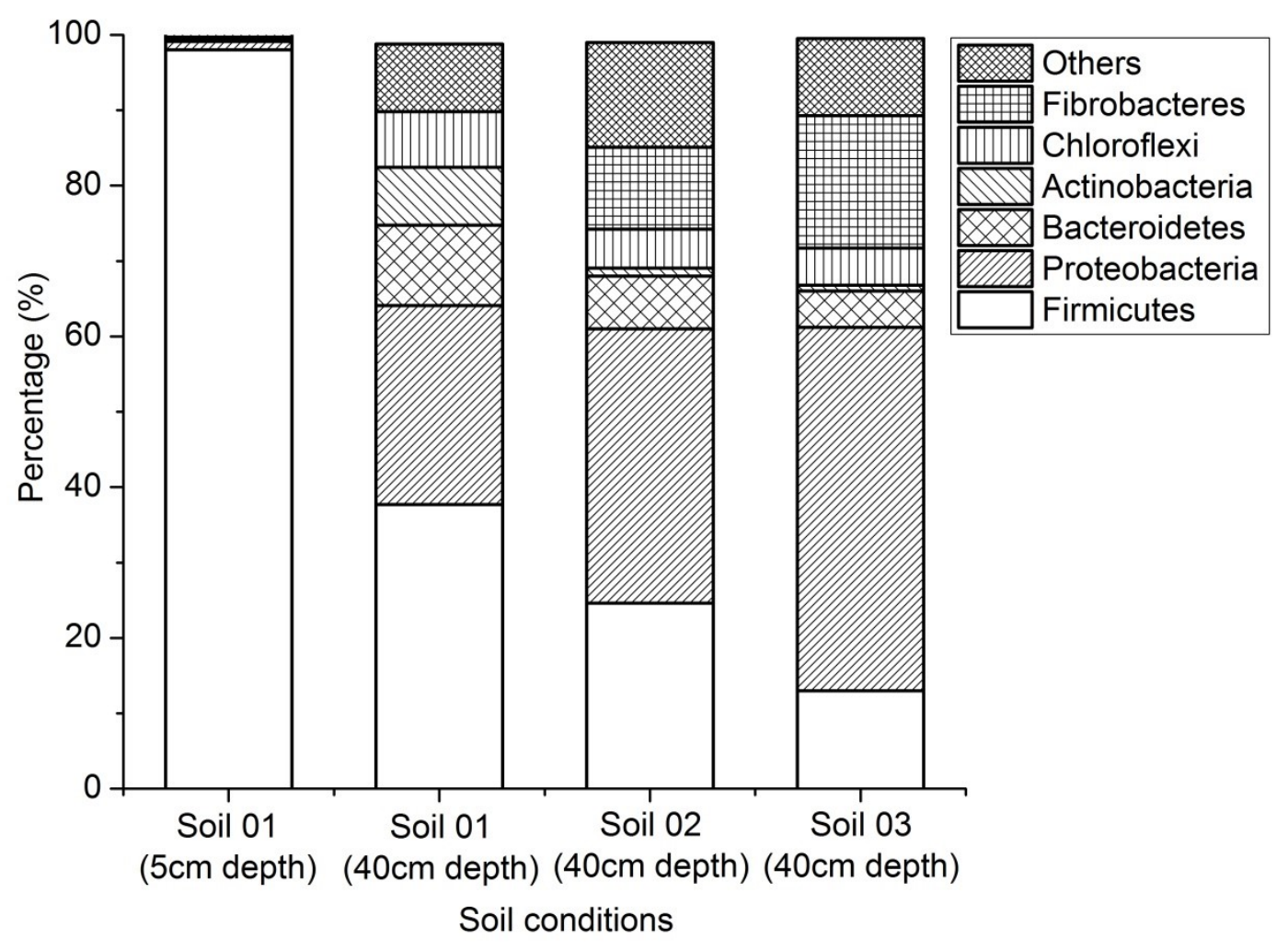

Fig. 10 Bacterial profile at phylum level of soils 


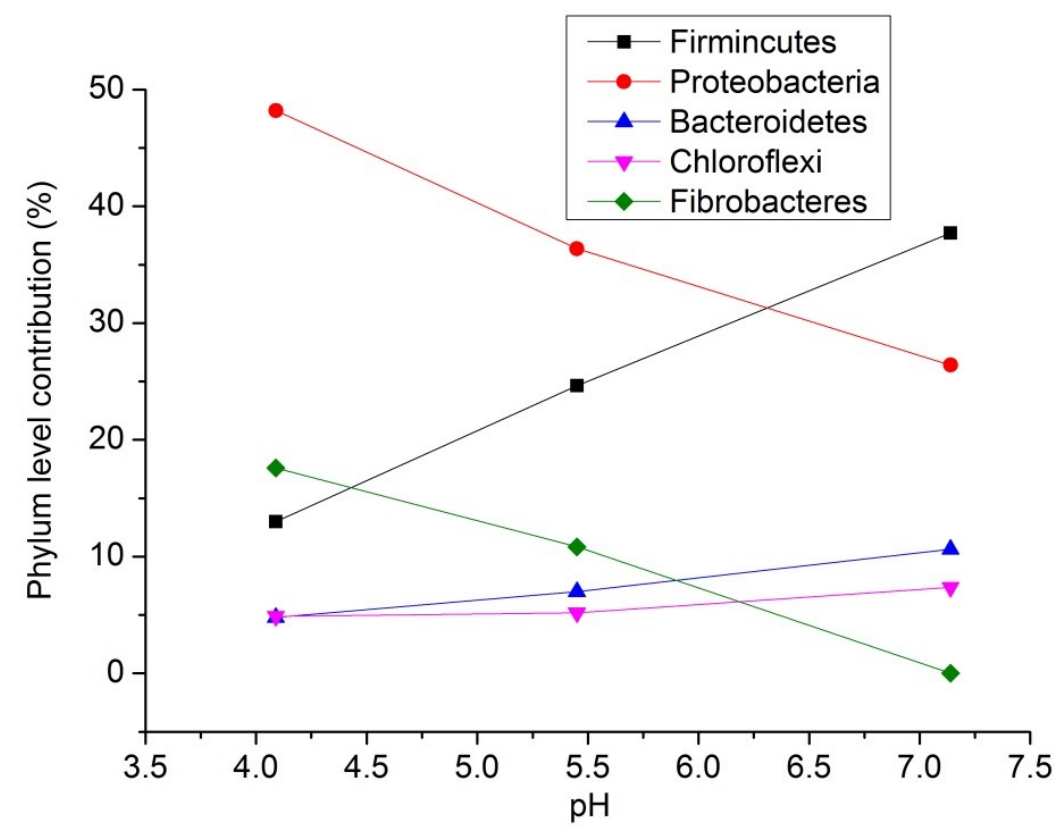

Fig. 11 Variation of phylum levelled bacteria over different $\mathrm{pH}$ of the medium 


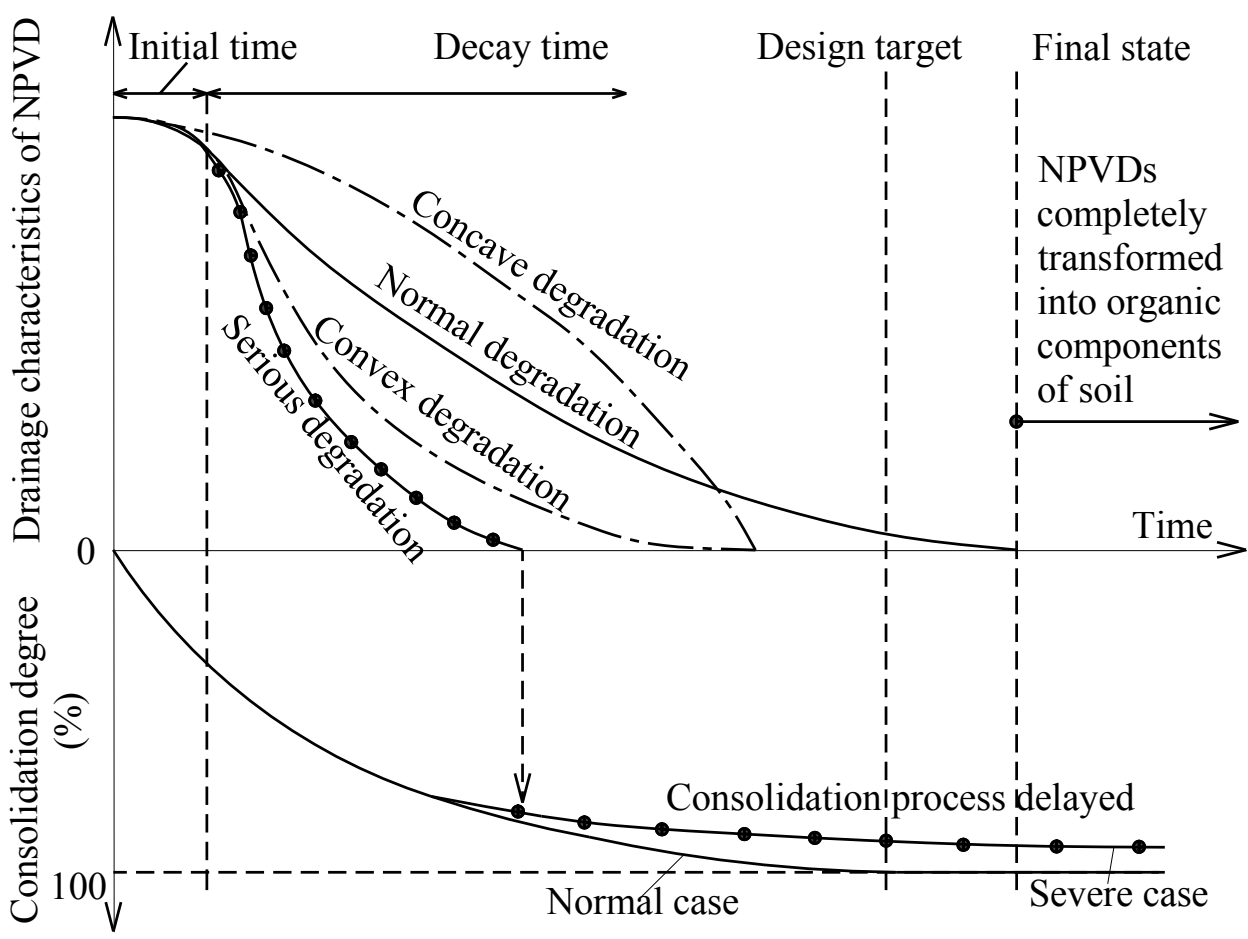

Fig. 12 Degradation of NPVDs in relation to consolidation process of soil 

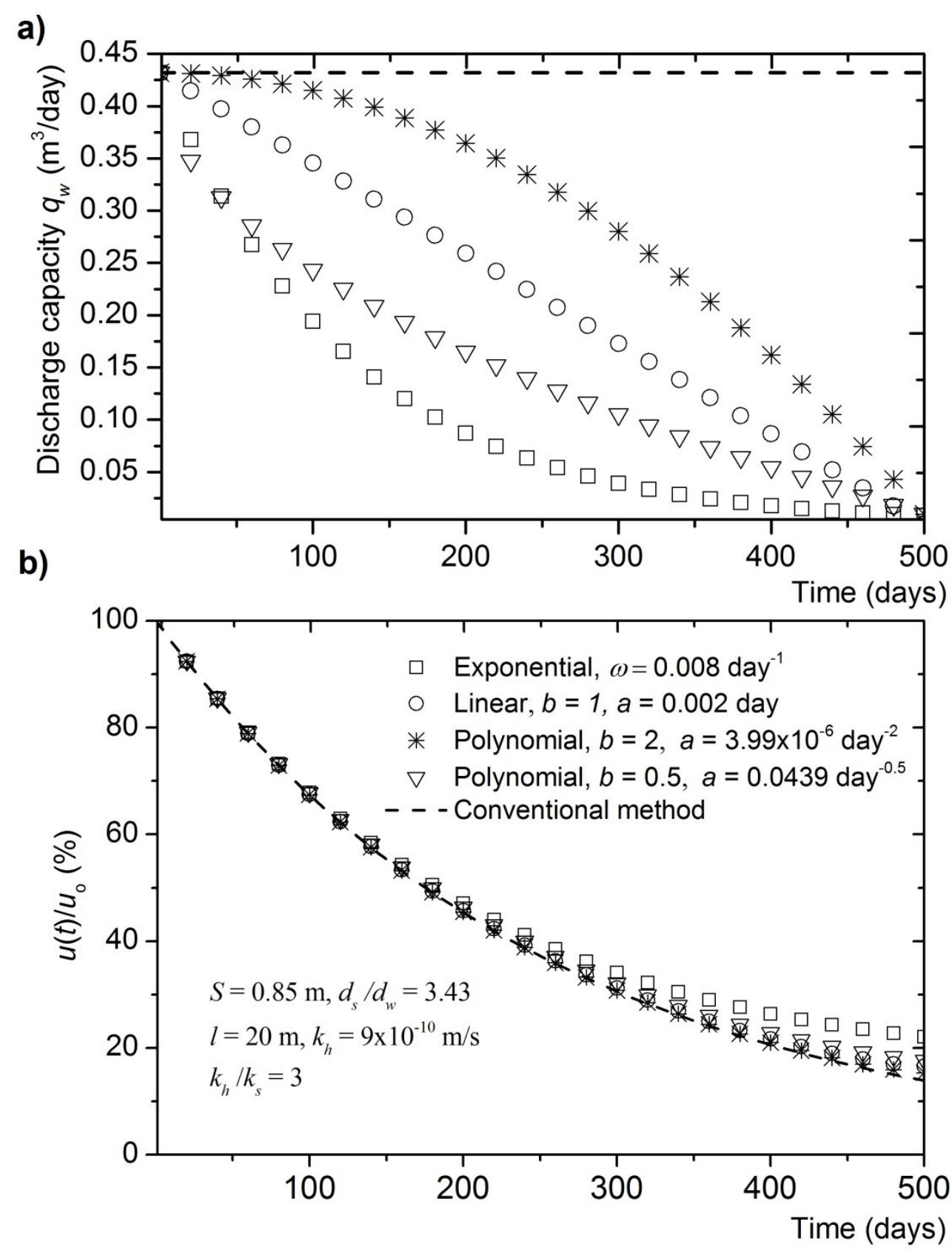

Fig. 13 Different degradation forms of $\left.q_{w}(t): a\right)$ discharge capacity; and $b$ ) corresponding dissipation of excess pore pressure. 

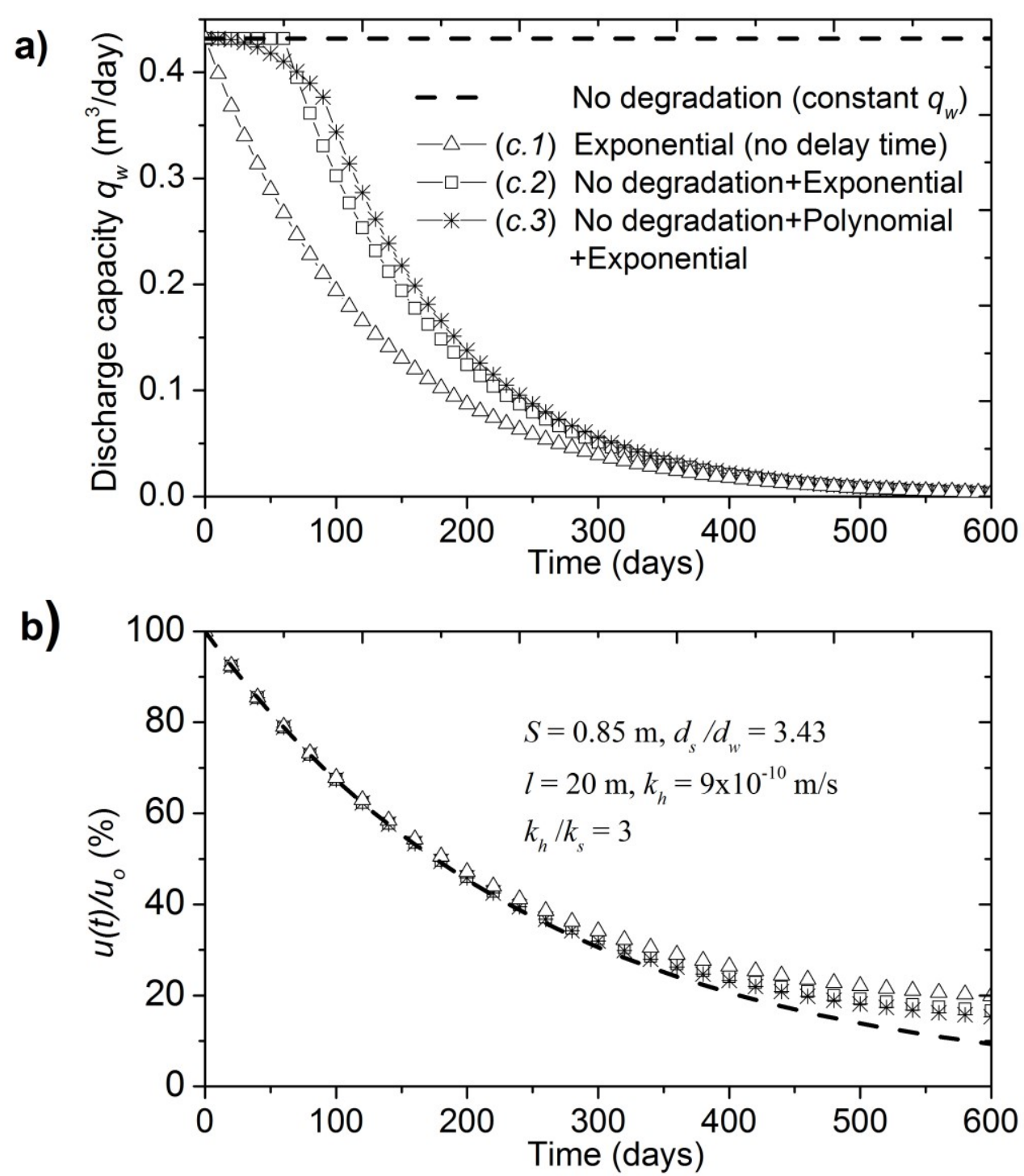

Fig. 14 Dissipation of excess pore pressure considering different degradation forms of discharge capacity over time: $a$ ) combined different forms of degradation; $b$ ) corresponding dissipation of excess pore pressure 
APPENDIX A: Microbial Trees of Decayed Fibres Buried in Different Soils

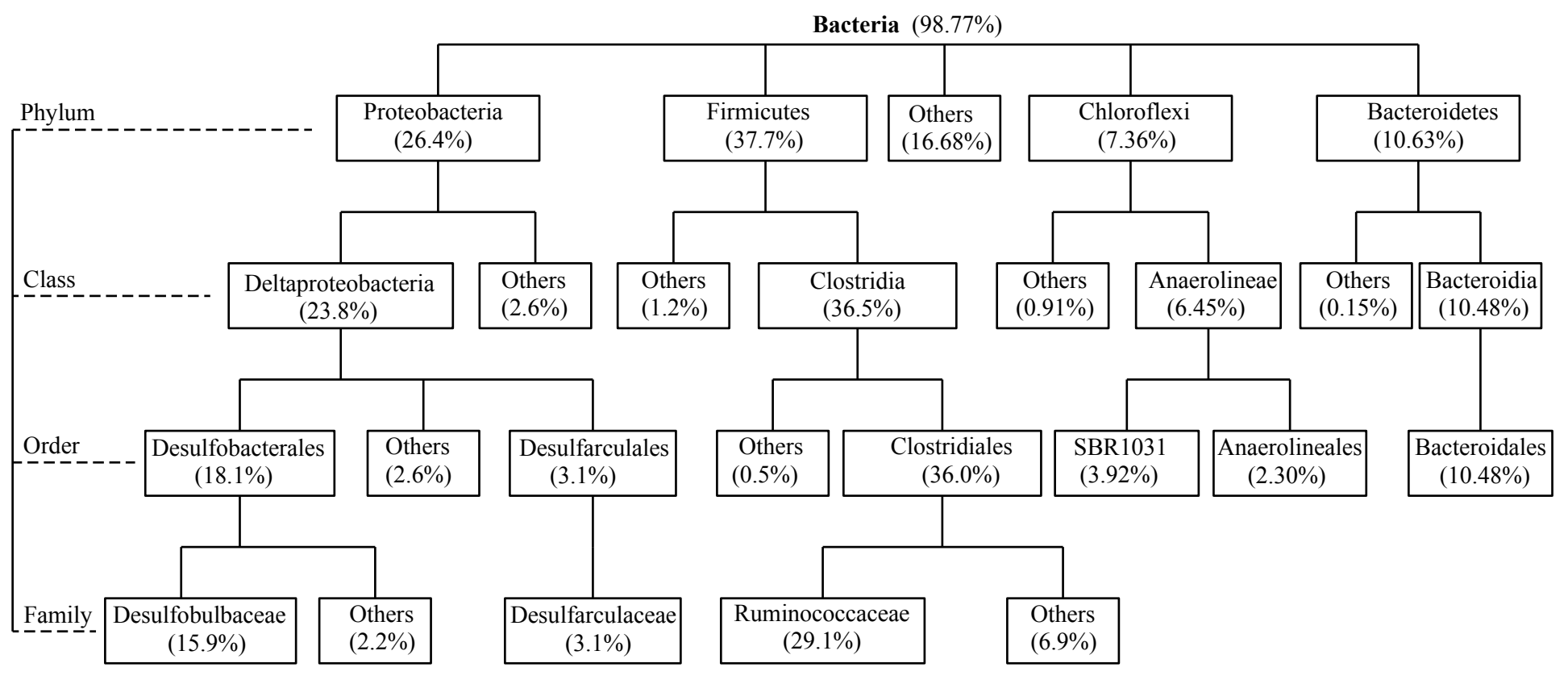

Fig. A1 Bacterial community in soil/container 1 (at $40 \mathrm{~cm}$ depth) 


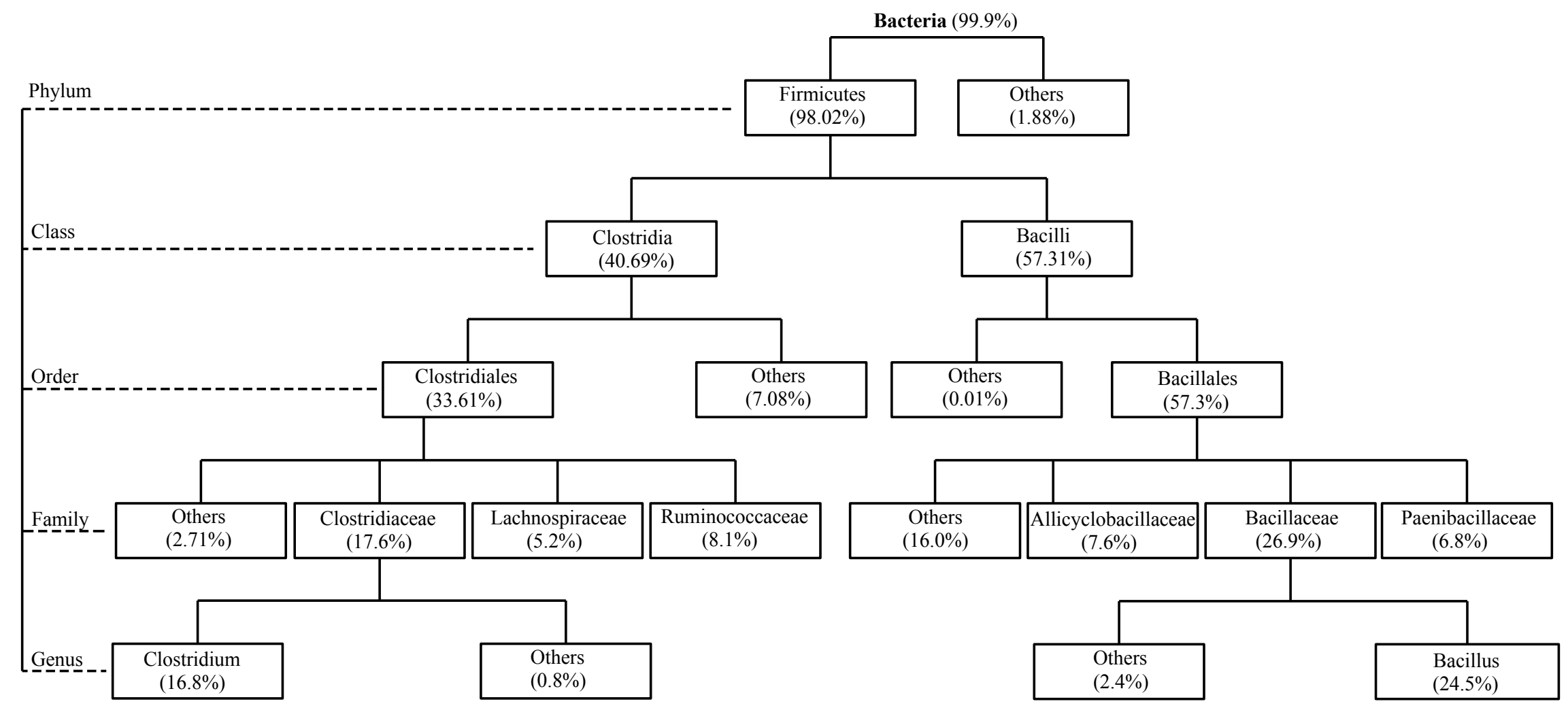

Fig. A2 Bacterial community at the surface layer of soil/container 1 (at $5 \mathrm{~cm}$ depth) 
Bacteria $(98.97 \%)$

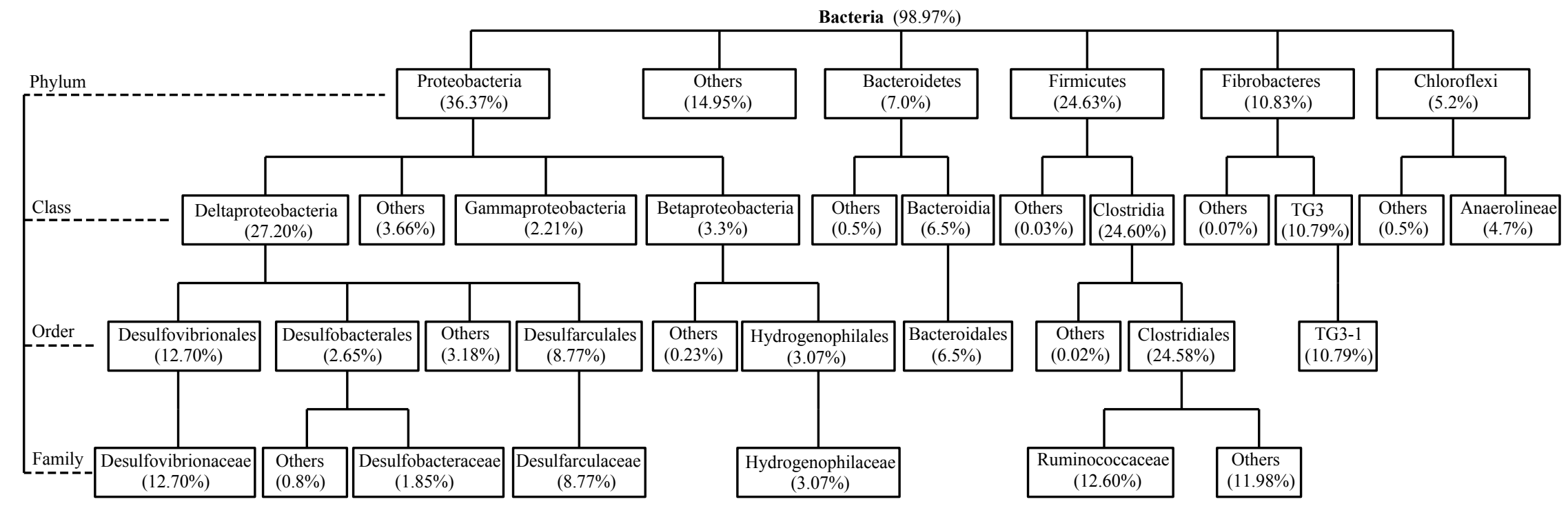

Fig. A3 Bacterial community in soil/container 2 (at $40 \mathrm{~cm}$ depth) 


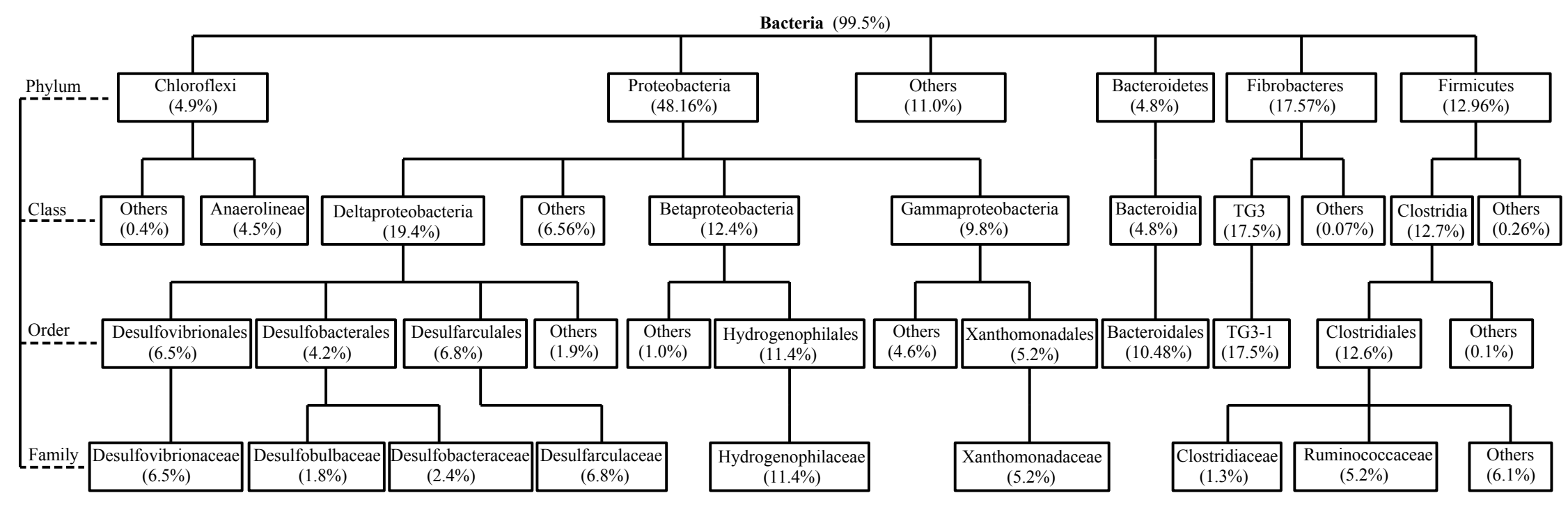

Fig. A4 Bacterial community in soil/container 3 (at $40 \mathrm{~cm}$ depth) 